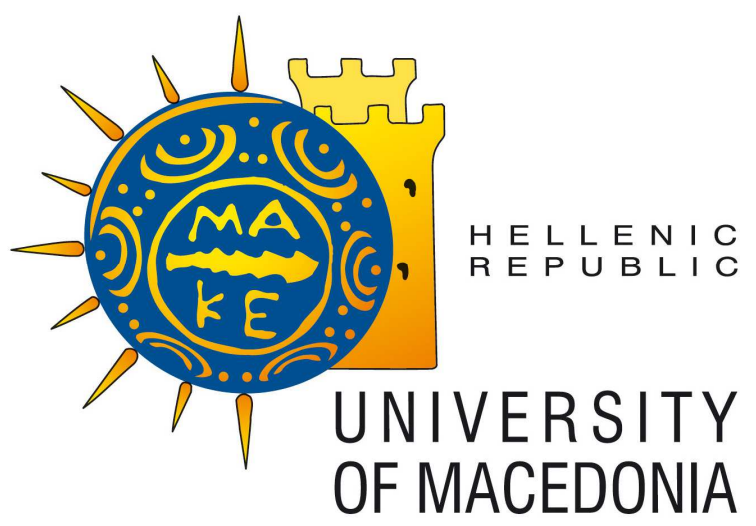

ISSN 1791-3144

\author{
University of Macedonia \\ Department of Economics
}

\author{
Discussion Paper Series
}

\title{
Long-Run Changes in Radiative Forcing and Surface Temperature: The Effect of Human Activity over the Last Five Centuries
}

Theologos Dergiades, Robert K. Kaufmann and Theodore Panagiotidis

\section{Discussion Paper No. 6/2019}

Department of Economics, University of Macedonia, 156 Egnatia str, 54006

Thessaloniki, Greece, Fax: + 30 (0) 2310891292

http://www.uom.gr/index.php?newlang=eng\&tmima=3\&categorymenu=2 


\title{
Long-Run Changes in Radiative Forcing and Surface Temperature: The Effect of Human Activity over the Last Five Centuries
}

\author{
Theologos Dergiades ${ }^{a}$, Robert K. Kaufmann ${ }^{\mathrm{b} *}$ and Theodore Panagiotidis ${ }^{\mathrm{c}}$ \\ a School of Science and Technology, International Hellenic University, 14th km Thessaloniki/Moudania, \\ 57001 Thermi, Greece. t.dergiades@ihu.edu.gr \\ b Department of Earth and Environment, Center for Energy and Environmental Studies, 675 \\ Commonwealth Avenue, Boston University, Boston MA 02215, United States. Kaufmann@bu.edu \\ c Department of Economics, University of Macedonia, 156 Egnatia Str., Thessaloniki 540 06, Greece. \\ tpanag@uom.edu.gr
}

September 2015

\begin{abstract}
We test two hypotheses that are derived from the anthropogenic theory of climate change. The first postulates that a growing population and increasing economic activity increase anthropogenic emissions of radiatively active gases relative to natural sources and sinks, and this alters global biogeochemical cycles in a way that increases the persistence of radiative forcing and temperature. The second postulates that the increase in the persistence of radiative forcing transmits a stochastic trend to the time series for temperature. Results indicate that the persistence of radiative forcing and temperature changes from $\mathrm{I}(0)$ to $\mathrm{I}(1)$ during the last 500 years and that the $\mathrm{I}(1)$ fingerprint in radiative forcing can be detected in a statistically measureable fashion in surface temperature. As such, our results are consistent with the physical mechanisms that underlie the theory of anthropogenic climate change.
\end{abstract}

Keywords: Global climate change; radiative forcing; surface temperature.

JEL Classification : C12, Q51, Q54

*Corresponding author, e-mail: Kaufmann@bu.edu, Tel: +1 617353 3940, fax: +1 6173535986. 


\section{Introduction}

Two foci for statistical analyses of global climate change are the times series properties of radiative forcing and global temperature and whether natural and/or anthropogenic components of radiative forcing are related to surface temperature in a statistically meaningful way. These foci evolve from concerns that ignoring the properties of the time series could lead to ambiguous results. Specifically, if the time series for radiative forcing and/or surface temperature contain a stochastic trend, statistical methods that assume the data are stationary, such as ordinary least squares (OLS), could generate spurious regression results. That is, the standard diagnostic statistics that are used to evaluate results generated by OLS will indicate a statistically meaningful relation among non-stationary time series in about 85 percent of the cases even when the data generating processes are unrelated (Hendry and Juselius, 2000).

Efforts to understand the time series properties of climate data start with Bloomfield and Nychka (1992) and Woodward and Gray (1993, 1995). These studies find that global temperature is non-stationary but are split regarding the data generating process (DGP); a deterministic or stochastic trend. Two studies (Nychka, 1992; Woodward and Gray, 1993) find that the temperature time series contains a deterministic trend while Woodward and Gray (1995) find evidence for a stochastic trend. Recent studies such as Stern and Kaufmann (2000) and Kaufmann et al. (2013) report additional evidence for a stochastic trend in temperature. Overall, the literature contains considerable evidence that the temperature time series is I(1). Conversely, many studies find that the time series for the radiative forcing of greenhouse gases (e.g. carbon dioxide, methane, nitrous oxide, CFCs), are I(2), while the radiative forcing of sulfur aerosols and solar insolation generally are I(1) (Stern and Kaufman, 1999; Stern and Kaufmann, 2000; Kaufmann et al., 2006a). Given that the radiative forcing of greenhouses gases (and mainly of carbon 
dioxide) are integrated one order higher than that of temperature, these differences would seem to preclude a relation between temperature and aggregate radiative forcing.

Analysts attempt to reconcile this seeming contradiction in several ways. One approach argues that univariate tests, especially the Augmented Dickey-Fuller (ADF) statistic, do not generate reliable results for the temperature time series. Visual examination of the time series for surface temperature during the instrumental record (1850-present) indicates that values vary greatly from year to year. This variability suggests that if the anthropogenic components of radiative forcing affect climate by altering surface temperature, this signal may be obfuscated by natural variability, which implies that the temperature time series has a low signal to noise ratio (Stern and Kaufmann, 2000). When applied to such time series, the ADF statistic (and other unit root tests) rejects the null hypothesis too frequently when the true DGP is a random walk with noise and the noise is large compared to the signal (Enders, 1995; Hamilton, 1994). In a finite sample, reducing the signal to noise ratio increases the probability that the test will indicate a trend stationary variable, a type I error (Enders, 1995). This conclusion is reinforced by Monte Carlo simulations (Schwert, 1989; Phillips and Perron, 1988; Kim and Schmidt, 1990). Conversely, these effects may be offset by the presence of deterministic cycles, which may bias inferences in favor of failing to reject the null hypothesis of a unit root (Robinson, 1994).

A second approach exploits the notion of cointegration (using univariate or multivariate framework) to examine the time series properties of temperature and radiative forcing. Implementing a univariate approach, Kaufmann et al. (2006a; 2011) find that the radiative forcing of greenhouse gases, anthropogenic sulfur emissions, and solar insolation cointegrate with temperature over a variety of sample periods as indicated by 
ADF tests conducted on the residuals of the cointegrating regression. ${ }^{1}$ If a low signal to noise ratio obfuscates the stochastic trend in the temperature time series, multivariate test statistics can be used to evaluate whether the time series for temperature and radiative forcing have the same order of integration and if they do, whether they share the same stochastic trend (i.e. do they cointegrate). The hypothesis that surface temperature and radiative forcing share the same stochastic trend is based on physical principles; models that simulate climate for the planet as a whole (i.e. zero dimensional climate models) can be rewritten as cointegration/error-correction models (Kaufmann et al., 2013). Consistent with this theoretical underpinning, several empirical studies indicate that the time series for temperature and radiative forcing are I(1) and share the same stochastic trend. For example, Stern and Kaufmann (2000) employ a structural time series approach and find that the radiative forcing of greenhouse gases, solar radiation, and anthropogenic sulfur emissions can account for stochastic trends in Northern and Southern Hemisphere temperatures. Using the Johansen (1995) cointegration approach, Kaufmann and Stern (2002) find that temperature cointegrates with radiative forcing and that this cointegrating relation must include the radiative forcing of greenhouse gases, anthropogenic sulfur emissions, and solar insolation.

A third approach argues that temperature is neither stationary nor integrated order one, but rather is trend stationary with a break. Gay et al. (2009) find that they cannot reject the null hypothesis that global temperature and temperatures in the Northern and Southern Hemispheres are trend stationary with a one time permanent shock in 1977, 1985, and 1911, respectively. In response, Kaufmann et al. (2010; 2013) argue that: (1) there is no physical basis for radiative forcing to evolve in a deterministic manner, (2) the time series for radiative forcing cannot be modeled empirically as trend stationary with a

\footnotetext{
${ }^{1}$ A high noise to signal ratio could cause these results to 'over-reject' the null of no-cointegration.
} 
one-time shock, (3) cointegration and error-correction models generate a more accurate in-sample forecast than the trend stationary model, and (4) Monte Carlo simulations of the cointegration/error-correction model can generate time series for temperature that appear to be trend-stationary-with-a-break when analyzed with the statistical methodology used by Gay et al. (2009).

We build on these results by compiling time series for temperature, greenhouse gas concentrations $\left(\mathrm{CO}_{2}, \mathrm{CH}_{4}, \mathrm{~N}_{2} \mathrm{O}, \mathrm{CFC}-12, \mathrm{CFC}-11\right)$, anthropogenic sulfur emissions, the Southern Oscillation Index, volcanic activity, and solar insolation over a five hundred year period (1500-2011) and testing two hypotheses that are implied by the anthropogenic theory of climate change. According to this theory, forcings that are associated with human activity (e.g. increases in the atmospheric concentration of $\mathrm{CO}_{2}$ due to anthropogenic emissions) have little effect on climate prior to the Industrial Revolution because human actions have little effect on global biogeochemical cycles during this period. After the Industrial Revolution, changes in the types and magnitude of human activities increase human impacts on global biogeochemical cycles. These impacts lead to significant changes in radiative forcing and ultimately, global temperature. This general description leads to two hypotheses about how changes associated with the Industrial Revolution can be used to test indirectly the anthropogenic theory of climate change:

Hypothesis I. If a growing population and increasing economic activity increase anthropogenic emissions of radiatively active gases relative to natural sources and sinks, this will alter global biogeochemical cycles. Such alterations will change the persistence of the time series for radiative forcing and temperature over time (e.g. from $\mathrm{I}(0)$ to $\mathrm{I}(1)$ ). This first hypothesis is evaluated by estimating unit-root tests from rolling windows of different lengths and testing for a single change in persistence. The time series for radiative forcing changes from $\mathrm{I}(0)$ to $\mathrm{I}(1)$ concurrent with the Industrial Revolution. 
About eighty years later, the time series for temperature undergoes the same change. Together, these results are consistent with the hypothesis that human activities alter biogeochemical cycles, radiative forcing, and temperature.

Hypothesis II. If the persistence of radiative forcing is affected by human interventions in biogeochemical cycles, these actions will impart a stochastic trend to the time series for radiative forcing. This stochastic trend should be present in the time series for temperature. As such, there should be a cointegrating relation between temperature and radiative forcing. This second hypothesis is evaluated by testing whether temperature and total radiative forcing cointegrate over different periods. Results generated identify a long-run relationship between the global average radiative forcing and Northern Hemisphere temperature that is robust to the statistical methodology and the sample period. The presence of a cointegrating relation is consistent with hypothesis II.

Although our statistical results are consistent with Hypotheses I and II, this consistency does not establish a direct causal link between human activities and temperature. This link cannot be established using statistical methods because data for anthropogenic emissions of greenhouse gases and sulfur are not available for the 500 year sample period. As such, our methods cannot explicitly link human activities to emissions to concentrations (and radiative forcing) and ultimately temperature. Despite this obstacle, we cite first principles and scientific observations to argue that human activities are responsible for increased concentrations, which change the persistence of radiative forcing, and that this change generates a long-run relation between radiative forcing and surface temperature.

These results and methods used to obtain them are described in the subsequent sections. The second section describes the data for temperature and radiative forcing and the econometric methodology that is used to test for a change in persistence, the degree to which temperature and radiative forcing are cointegrated, and how their long-run 
relationship evolves over time. These results are described in the third section. The fourth section discusses the empirical findings with regard to the two hypotheses about the effect of human activity on global climate. Finally, the last section concludes.

\section{Data and Methodology}

\subsection{Data Sources}

The data include annual time series from 1500 to 2011 for; (1) eight components of radiative forcings ${ }^{2}$ (carbon dioxide $\left(\mathrm{CO}_{2}\right)$, methane $\left(\mathrm{CH}_{4}\right)$, nitrous oxide $\left(\mathrm{N}_{2} \mathrm{O}\right)$, chlorofluorocarbons CFC-11 and CFC-12, solar insolation, tropospheric sulfates due to anthropogenic activity (Fig. 1), and stratospheric sulfates due to volcanic activity (Fig. 2), (2) the El Niño/Southern Oscillation (ENSO) index (Fig. 3) and (3) average surface temperature in the Northern Hemisphere (Fig. 4). Time series for the three trace gases (globally average concentrations of $\mathrm{CO}_{2}, \mathrm{CH}_{4}$ and $\mathrm{N}_{2} \mathrm{O}$ ) and temperature (in degrees of Celsius anomalies) are obtained from reconstructions developed by Robertson et al. (2001) and Ammann and Wahl (2007), respectively. ${ }^{3}$

The time series for the radiative forcing of solar insolation (Fig. 1) is from Goosse et al. $(2005)^{4}$ while the time series for stratospheric sulfates due to volcanic activity (Fig. 2) is from Tett et al. (2007). ${ }^{5}$ The radiative forcing of two important chlorofluorocarbons (CFC-11 and CFC-12; both zero before 1949 and 1938, respectively-Fig. 1) and the radiative forcing due to anthropogenic sulphur emissions (zero before 1850-Fig. 1) come

\footnotetext{
${ }^{2}$ Radiative forcing is measured in watts per square meter $\left(\mathrm{W} / \mathrm{m}^{2}\right)$.

3 Temperature data are expressed as anomalies (with respect to the mean temperature for the period 1902 1980) in degrees (of Celsius). The temperature reconstruction in Ammann and Wahl (2007) ends in 1980; we extend the sample through 2011 using instrumental records. Data can be recovered from the NOAA paleoclimatology database (http://www.ncdc.noaa.gov/paleo/). The reconstructions of $\mathrm{CO}_{2}, \mathrm{CH}_{4}$ and $\mathrm{N}_{2} \mathrm{O}$ in Robertson et al. (2001) end in 1997; we extend the sample through 2011 using data that come from the Goddard Institute for Space Studies (GISS) (http://www.giss.nasa.gov/). Finally, the atmospheric concentrations of the three trace gases are converted to radiative forcing using the formulae in Kaufmann et al., (2011).

4 The reconstruction in Goose et al. (2005) ends in 2000; we extend the sample through 2011 using data that come from the Goddard Institute for Space Studies (GISS) (http://www.giss.nasa.gov/).

5 The volcanic activity in Tett et al. (2007) ends in 2000; we extend the sample through 2011 using data that come from Stern and Kaufmann (2014).
} 
from Stern and Kaufmann (2014). ${ }^{6}$ The index for El Nino/La Nina events (Fig. 3) is obtained from Li et al. (2011). ${ }^{7}$ Finally, the time series for aggregate forcing (Fig. 1) is constructed by adding all forcing components that contain a stochastic trend. ${ }^{8}$

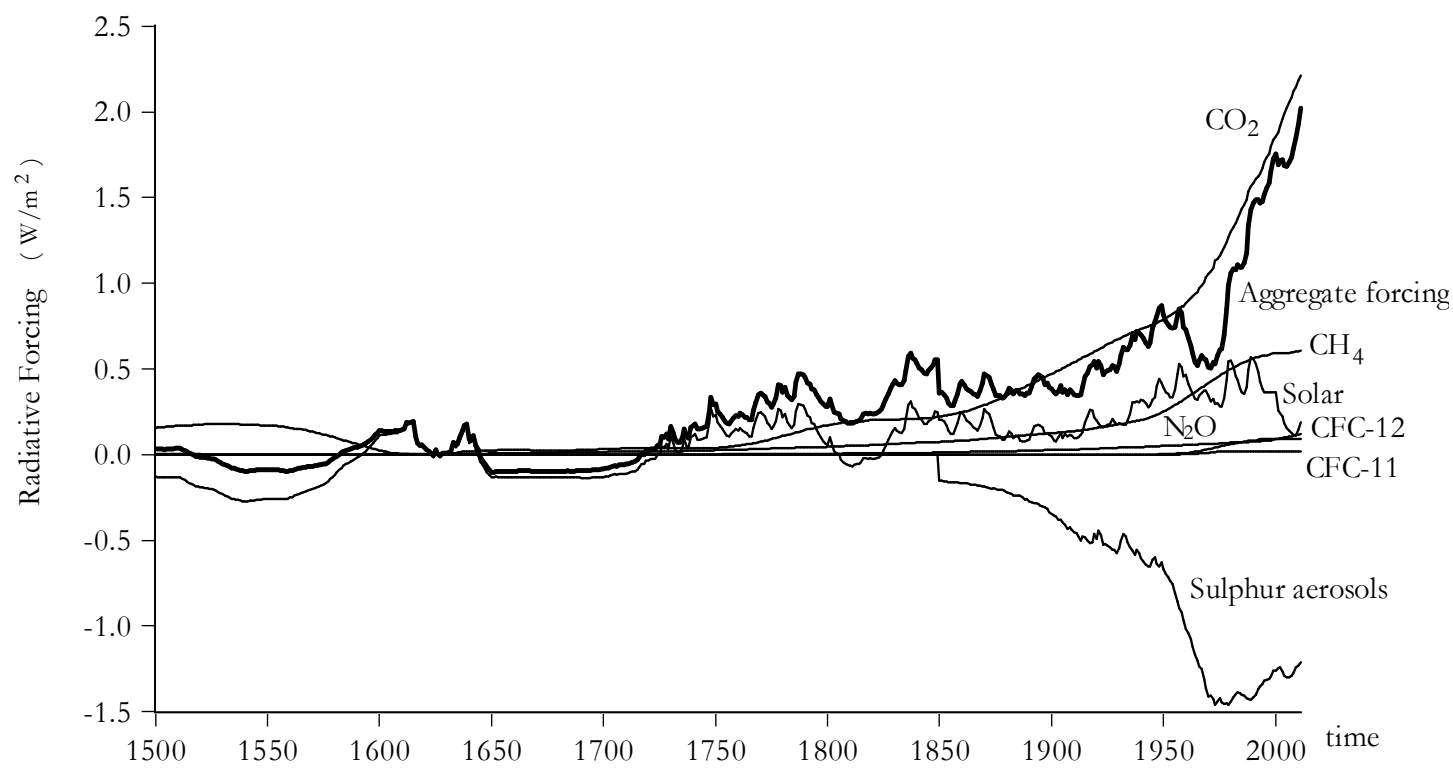

Fig. 1. Radiative forcing components
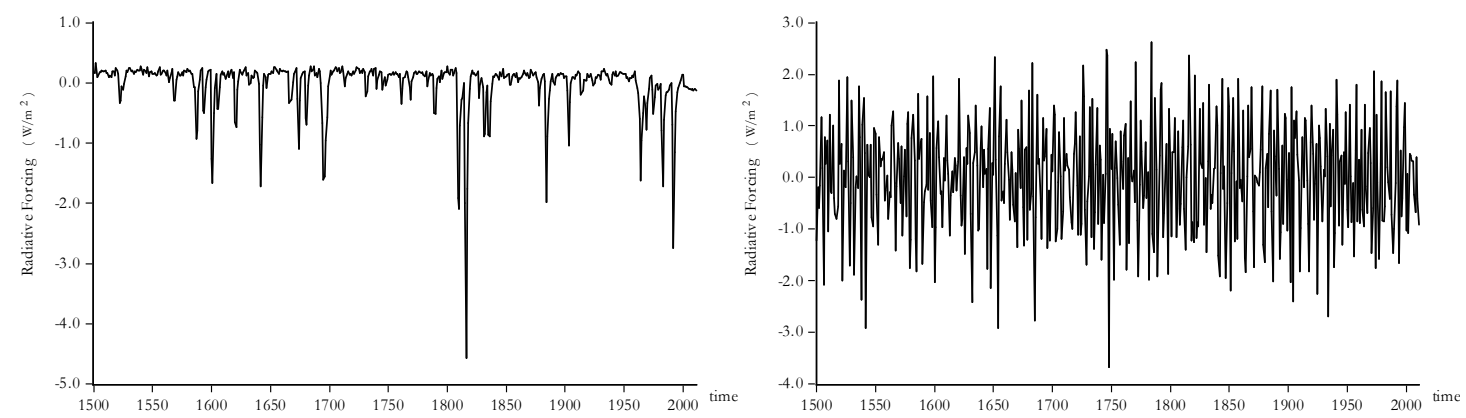

Fig. 2. Volcanic radiative forcing

Fig. 3. El Nino/Southern Oscillation (ENSO) index

\footnotetext{
${ }^{6}$ The time series are available at: http://www.sterndavidi.com/datasite.html

7 The ENSO index in Li et al. (2011) ends in 2002; we extend the sample through 2011 using data for the multivariate ENSO index that come from NOAA's database.

${ }^{8} \mathrm{At}$ this point, we need to mention that the aggregate radiative forcing series includes forcing components that contain an I(1) or an I(2) stochastic trend. Hence, seven components are included $\left(\mathrm{CO}_{2}, \mathrm{CH}_{4}, \mathrm{~N}_{2} \mathrm{O}\right.$, chlorofluorocarbons CFC-11 and CFC-12, solar insolation and tropospheric sulfates due to anthropogenic activity). The rationale of such a partitioning relies on the notion of cointegration, which seeks to match stochastic trends. Volcanic forcing as an $\mathrm{I}(0)$ component is not included in the aggregate forcing series, but it will relate to temperature through the residuals of the equilibrium relationship, once cointegration testing is conducted.
} 


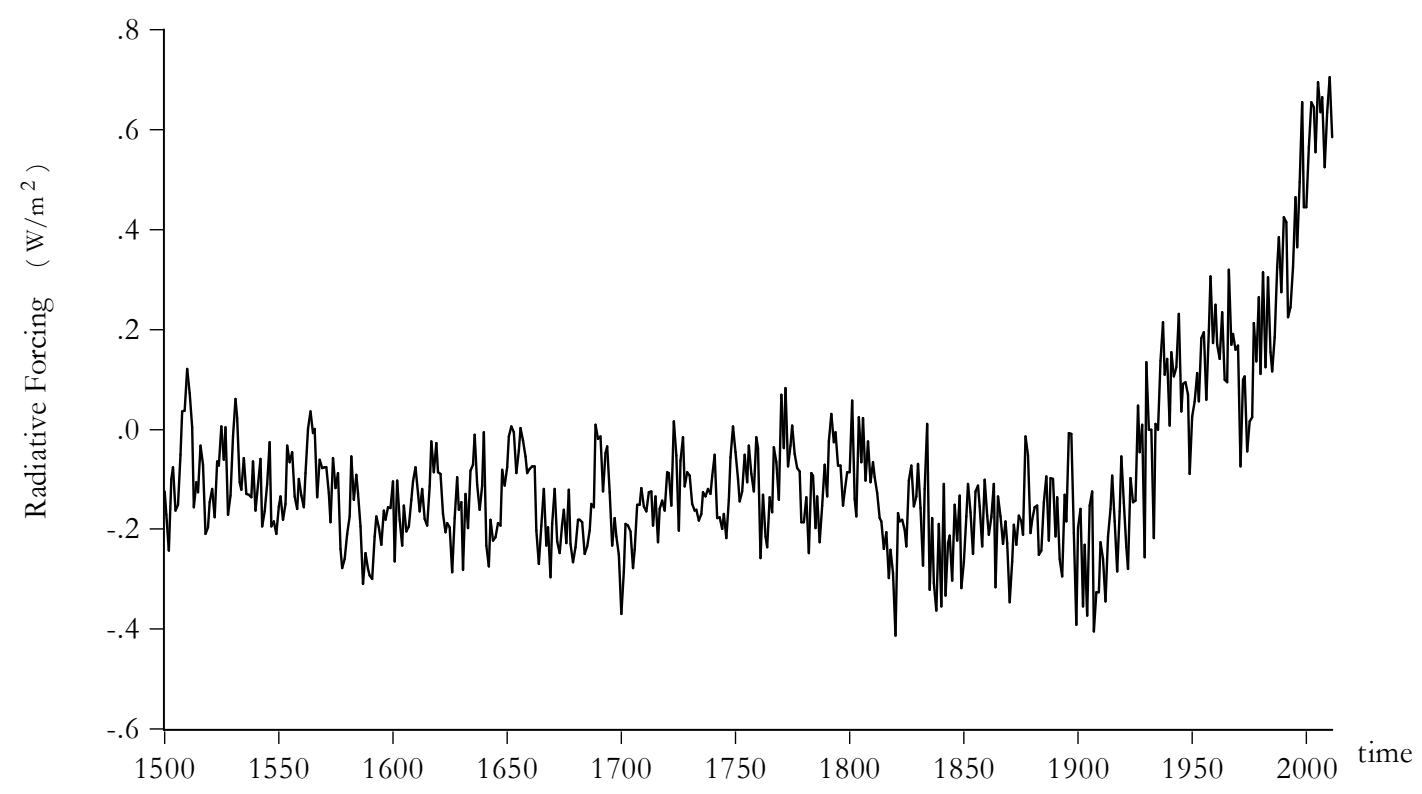

Fig. 4. Northern Hemisphere temperature anomaly

\subsection{Econometric Methodology}

\subsubsection{Preliminary analysis and Unit Root testing}

When climate data are tested for a unit-root, special care must be devoted to cyclical patterns because ignoring their presence may bias inferences in favor of failing to reject the null hypothesis of a unit root. Visual inspection suggests that the time series for temperature and aggregate forcing embody cyclical behavior. To remove these cyclical components, we use equation (1) to fit a periodic sinusoid function that accounts for three prominent solar cycles: the eleven year Schwabe cycle (see for example Qu and Xie, 2013), the twenty-two year Hale cycle (see for example Mursula et al., 2001) and the century-long Gleissberg cycle (see for example Ogurtsov et al., 2002):

$$
S_{t}=\beta_{0}+\sum_{i=1}^{3} \beta_{1, i} \sin \left(\left(2 \pi / m_{i}\right) t\right)+\sum_{i=1}^{3} \beta_{2, i} \cos \left(\left(2 \pi / m_{i}\right) t\right)+\varepsilon_{t}
$$

in which $S_{t}$ is the time series for temperature or radiative forcing, $\beta_{0}, \beta_{1, i}$ and $\beta_{2, i}$ (with $i=1,2,3$ ) are parameters to be estimated, sin and cos denote the sine and cosine 
functions, respectively, $\pi \approx 3.14, t$ is a time trend and finally, $m_{i}$ represents the selected cycle lengths in years (with $i=1,2,3$ ).

Because the lengths of the solar cycles are not known a priori, we estimate Eq. 1 with a range of lengths. Specifically, $m_{1}, m_{2}$ and $m_{3}$ are assigned values that vary between ten and fourteen years (to capture the Schwabe cycle), between twenty and twenty-four years (to capture the Hale cycle) and between 80 and 130 years (to capture the Gleissberg cycle), respectively. These ranges create 1,275 combinations for $m_{1}, m_{2}$ and $m_{3}$. Each combination is used to estimate equation (1) and we retain the combination that generates the best fit. ${ }^{9}$ Results for the temperature series indicate that the coefficients associated with the short- and medium-run cycles are not statistically different from zero. As a result, we re-estimate a version of Eq. 1 that specifies the long-run cycle only. The final specification identifies a significant long-run cycle with a period of 115 years. The decycled temperature series is compiled from the recovered residuals.

This method is modified to remove cycles from the time series for aggregate forcing (the sum of all forcings that include a stochastic trend-see Fig. 1). None of the six of the forcings in Fig. $1\left(\mathrm{CO}_{2}, \mathrm{CH}_{4}, \mathrm{~N}_{2} \mathrm{O}, \mathrm{CFC}-11, \mathrm{CFC}-12\right.$ and anthropogenic sulphur emissions) suggest a periodic variation. Instead, we focus on solar forcing, which clearly shows cyclical patterns. For a sample that includes observations from the first two centuries (from 1500 through 1728), the time series for solar insolation seems to contain only the Gleissberg cycle. Conversely, the two shorter cycles are present in a sample that contains observations from the three most-recent centuries (from 1729 through 2011).

Because of this seeming change, estimating Eq. 1 for the complete sample would introduce artificial cycles of shorter durations into the first two centuries (induced by the last three centuries of the sample). To avoid introducing artificial cycles into the 1500 -

\footnotetext{
${ }^{9}$ Based on the Schwarz Information Criterion.
} 
1728 subsample, we remove cycles from the time series for solar insolation in two steps. In the first step, we identify the long-run cycle (80 to 130 years) that best fits ${ }^{10}$ the first part of the sample (1500-1728). In the second step, we find the combination that best fits the three cycles discussed earlier. Essentially, we estimate Eq. 1 for a range of cycle lengths for the second part of the sample, while the cycle length for the first part is held fixed. ${ }^{11}$ The non-regular components of the series are compiled using the residuals from the optimal specification. ${ }^{12}$ The decycled series for aggregate forcing ${ }^{13}$ (Figure 5, F hereafter), is compiled by adding the remaining six forcings from Fig. 1 to the time series for solar forcing from which cycles have been removed.

As described in the introduction, noise also can affect the ability of ADF type unit root tests to detect stochastic trends. Visual examination of Fig. 4 indicates that the time series for temperature is quite noisy compared to the time series for aggregate forcing $(F)$. Therefore, we remove the noise from the former. To remove noise from the temperature anomalies, ${ }^{14}$ we follow Stern and Kaufmann $(2000)^{15}$ and estimate a general state-space model using equations 2-4:

$$
\begin{aligned}
& S_{t}=A_{t}+W_{t} \\
& A_{t+1}=A_{t}+\lambda_{t}+\eta_{t} \\
& \lambda_{t+1}=\lambda_{t}+v_{t}
\end{aligned}
$$

in which $S_{t}$ is the temperature series, the signal in the temperature time series is represented by the state variable $A_{t}, W_{t}$ represents the noise of the series modeled as an $\operatorname{AR}(p)$ process, $\lambda_{t}$ is a random walk process, and white noise processes are represented

\footnotetext{
10 The optimal fit suggests a cycle length of 130 years and it is selected based on the Schwarz Information Criterion.

11 Specifically, $m_{1}, m_{2}$ and $m_{3}$ receive values that vary from 10 to 14 , from 20 to 24 and from 80 to 130 , respectively.

12 The optimal specification (based on SIC) for the solar forcing series implies significant cycle lengths that are equal to 12 years $\left(m_{1}=12\right), 20$ years $\left(m_{2}=20\right)$ and 94 years $\left(m_{3}=94\right)$.

13 The volatility of the aggregate forcing series appears to change after 1728 . This is mainly due to the solar forcing component. The observed change in volatility is not addressed in our analysis.

14 The denoising process in conducted for the decycled temperature anomalies series.

15 We are grateful to an anonymous referee for pointing this out.
} 
by $\eta_{t}$ and $v_{t}$. The Kalman filter is used to estimate the system of equations (2) to (4), which generates an estimate for series $A_{t}$; the noise-free series for temperature (Figure 5, $T$ hereafter).

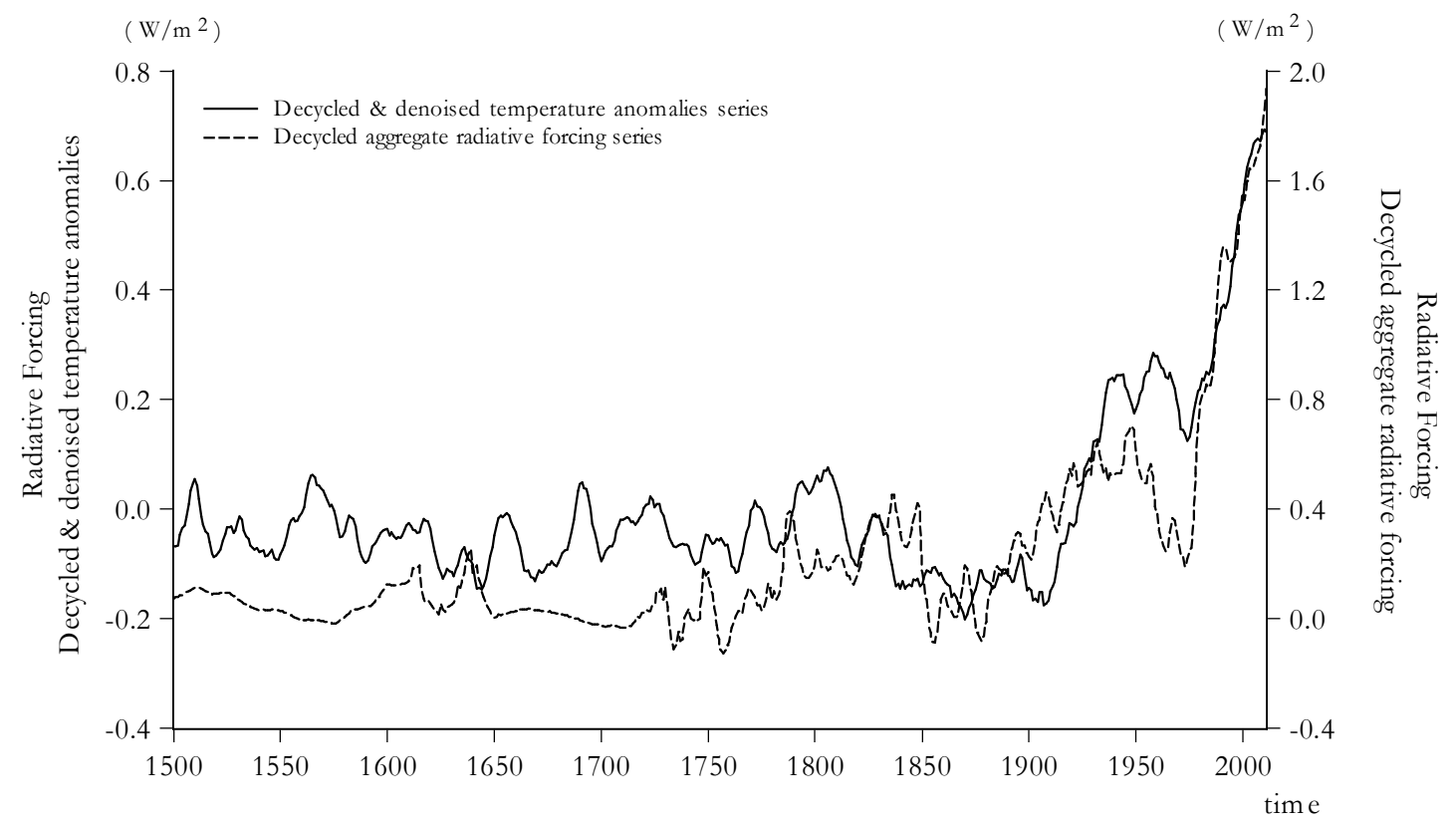

Fig. 5. Radiative forcing for: a) decycled \& denoised temperature anomalies and b) decycled aggregate radiative forcing

Fig. 5 indicates that $T$ and $F$ increase significantly during the last century. This rise suggests that both time series are not stationary. To identify the processes that generate the properties of $T$ and $F$, we use the non-linear KSS unit-root test (Kapetanios et al., 2003) from rolling windows of different sample sizes. The nonlinear KSS statistic can identify non-stationarity against globally stationary exponential smooth transition autoregressive (ESTAR) processes. This modification is needed because traditional unit-root tests are not robust if the true DGP is a non-linear stationary process. ${ }^{16}$

16 By conducting the BDS test (Brock et al. 1996) on the delinearized series of $T$ and $F$ (the delinearization is performed through a bivariate VAR specification), overwhelming evidence of nonlinearity emerges for both. The results are available upon request. 
The KSS test uses a univariate ESTAR specification, which can be reparameterised as follows:

$$
\Delta x_{t}=\phi x_{t-1}+\gamma x_{t-1}\left[1-\exp \left(-\theta x_{t-d}^{2}\right)\right]+\varepsilon_{t} \quad \text { with: } \theta \geq 0, \text { and } d \geq 1
$$

in which $x_{t}$ a mean zero stochastic process, $\phi$ and $\gamma$ are parameters, the expression within the brackets is the transition function ${ }^{17}$ with $\theta$ and $d$ as delay parameters, and $\varepsilon_{t} \sim$ iid $\left(0, \sigma^{2}\right)$. By allowing $x_{t}$ to be non-stationary in the middle regime $(\phi=0)$, the non-linear KSS statistic tests the null hypothesis $(\theta=0)$ of a unit root against the alternative $(\theta>0)$ that the process is non-linear but globally stationary (given that $-2<\gamma<0)$.

Because $\gamma$ cannot be identified under the null hypothesis, KSS use the following auxiliary regression (after implementing a first-order Taylor approximation to the ESTAR specification) to derive a $t$-type test statistic: ${ }^{18}$

$$
\Delta x_{t}=\delta x_{t-1}^{3}+\xi
$$

in which $\xi$ is the error. The null hypothesis can be restated as $\delta=0$ against the alternative $\delta<0$. The test statistic is given by $t_{N L}=\hat{\delta} /$ s.e. $(\hat{\delta})$. The limiting non-standard distribution of the $t_{N L}$ statistic $^{19}$ is derived (with the associated asymptotic critical values) in KSS. Overall, the $t_{N L}$ statistic is more powerful against stationary ESTAR processes than the standard ADF test (Kapetanios et al., 2003).

Finally, because the unit-root tests are estimated from rolling windows, we need to determine the window length. The absence of a priori information on the correct window

\footnotetext{
17 The transition function is bounded between 0 and 1 .

18 To account for serial correlation, the auxiliary regression may be augmented by lags of the depended variable. The lag length is determined through the usual information criteria.

${ }_{19}$ The asymptotic distribution of $t_{N L}$ is also derived for stochastic processes with non-zero means and/or linear trends.
} 
length forces us to estimate unit-root test statistics from rolling windows with six lengths. The shortest window includes 200 observations; subsequent windows increase by 50 observations until we reach a window with 450 observations. ${ }^{20}$ Therefore, the total number of unit-root tests that can be performed for a window with length $\kappa$, is equal to $(n-\kappa)+1$, where $n$ is the sample size.

\subsubsection{Test for Change in Persistence}

To formally analyze the times series for a change in persistence, we use the tests developed by Busetti and Taylor (2004) (hereafter B\&T) and Harvey et al. (2006) (hereafter HL\&T). The B\&T statistic examines the null hypothesis that a time series is $\mathrm{I}(0)$ across the entire sample against the alternative hypothesis that there is a change in persistence from $I(0)$ to $I(1)$ at an unknown breakpoint. This hypothesis is tested as follows:

$$
\begin{aligned}
& H_{1}\left(\mathscr{K}_{M}(.)\right) \equiv \max _{\tau \in\left[\tau_{l}, \tau_{u}\right]} \mathscr{K}_{M}(\tau) \\
& H_{2}\left(\mathscr{K}_{M}(.)\right) \equiv \int_{\tau \in\left[\tau_{l}, \tau_{u}\right]} \mathscr{K}_{M}(\tau) d \tau \\
& H_{3}\left(\mathscr{K}_{M}(.)\right) \equiv \log \left\{\int_{\tau \in\left[\tau_{l}, \tau_{u}\right]} \exp \left(\mathscr{K}_{M}(\tau)\right) d \tau\right\} \\
& \mathscr{K}_{M}(\tau)=\frac{[(1-\tau) T]^{-2} \sum_{t=[\tau T]+1}^{T}\left(\sum_{i=[\tau T]+1}^{t} \hat{\varepsilon}_{1, i}\right)^{2}}{[\tau T]^{-2} \sum_{t=1}^{[\tau T]}\left(\sum_{i=1}^{t} \hat{\varepsilon}_{0, i}\right)^{2}}
\end{aligned}
$$

in which, $\tau \in(0,1),\left[\tau_{l}, \tau_{u}\right]$ is a sub-interval of $(0,1), T$ is the sample size, and $\hat{\varepsilon}_{0, i}$ and $\hat{\varepsilon}_{1, i}$ are the OLS residuals from the regression of the examined series on a constant for the samples $t=1, \ldots,[\tau T]$ and $t=[\tau T], \ldots, T$, respectively. Under the same null hypothesis, B\&T test for a change from $\mathrm{I}(1)$ to $\mathrm{I}(0)$, using the reciprocal of $\mathscr{K}_{M}(\tau)$. The respective analogues for the equations (7), (8), and (9) are denoted as $H_{j}\left(1 / \mathscr{K}_{M}().\right)$, with $j=1,2$ and 3.

\footnotetext{
20 The exact length (in years) for each of the six implemented windows is: 200, 250, 300, 350, 400 and 450.
} 
The test statistics described above are severely oversized when the true DGP is I(1) throughout the sample. For this reason, we use the HL\&T statistic to test the null hypothesis that the time series is generated by an $\mathrm{I}(0)$ or $\mathrm{I}(1)$ process against the alternative hypothesis that the process changes from $\mathrm{I}(0)$ to $\mathrm{I}(1)$. This set of hypotheses is tested as follows:

$$
H_{j}\left(\mathscr{K}_{M}(.)\right)_{j, \min }=\exp \left(-b J_{\text {min }}\right) H_{j}\left(\mathscr{K}_{M}(.)\right) \quad \text { with } j=1,2,3
$$

in which, $H_{j}\left(\mathscr{K}_{M}(.)\right)_{j, \min }$ is the modified statistic, $b$ is a constant provided by Harvey $e t$ al. (2006) and $j_{\min }=\min _{\tau \in\left[\tau_{l}, \tau_{u}\right]} j_{1,[\tau T]}$, with $j_{1,[\tau T]}$ equals to $T^{-1}$ times the Wald statistic that corresponds to the test of the joint $\delta_{k+1}=\ldots=\delta_{9}=0$ hypothesis, in the following regression:

$$
y_{t}=\mathbf{x}_{t}^{\prime} \beta+\sum_{i=k+1}^{9} \delta_{i} t^{i}+u_{t}, \quad t=1, \ldots,[\tau T]
$$

When testing the alternative hypothesis of the opposite change (that is, $I(1)$ to $I(0)$ ), the $H_{j}\left(\mathscr{K}_{M}().\right)$ statistic in equation (11) is replaced with $H_{j}\left(1 / \mathscr{K}_{M}().\right)$ and the $j_{1,[\tau T]}$ factor is replaced with $j_{\min }^{R}=\min _{\tau \in\left[\tau_{l}, \tau_{u}\right]} j_{[\tau T], T}$, where $j_{[\tau T], T}$ is defined as $j_{1,[\tau T]}$ with the exception that specification (12) is now estimated for $t=[\tau T], \ldots, T$. The modified statistic is denoted as $H_{j}\left(1 / \mathscr{K}_{M}(.)\right)_{j, \min }$.

To identify the date when the DGP changes from $\mathrm{I}(0)$ to $\mathrm{I}(1)$ or from $\mathrm{I}(1)$ to $\mathrm{I}(0)$, Busetti and Taylor (2004) propose equations (13) and (14), respectively.

$$
\begin{aligned}
& \hat{\tau}=\arg \max _{\tau \in\left[\tau_{l}, \tau_{u}\right]} \Lambda(\tau) \\
& t=\arg \min _{\tau \in\left[\tau_{l}, \tau_{u}\right]} \Lambda(\tau)
\end{aligned}
$$

with

$\Lambda(\tau)=\frac{\sum_{t=[\tau T]+1}^{T} \hat{\varepsilon}_{1, t}^{2} /(T-[\tau T])^{2}}{\sum_{t=1}^{[\tau T]} \hat{\varepsilon}_{0, t}^{2} /[\tau T]^{2}}$ where, $\hat{\varepsilon}_{0, t}^{2}$ and $\hat{\varepsilon}_{1, t}^{2}$ are defined as previously 


\subsubsection{Cointegration Analysis}

The statistical methodology used to test for cointegration is based on Johansen (1995). For the $p$-dimensional I(1) process $\mathbf{y}_{t}$ we estimate a $\operatorname{VAR}(k)$ specification, which can be represented in error-correction form as:

$$
\Delta \mathbf{y}_{t}=\alpha \beta^{\prime} \mathbf{y}_{t-1}+\sum_{i=1}^{k-1} \Gamma_{i} \Delta \mathbf{y}_{t-i}+\boldsymbol{\varepsilon}_{t}
$$

where, $\alpha$ is the $p \times r$ matrix which represents the speed of adjustment to disequilibrium, $\beta$ is $p \times r$ matrix of the long-run coefficients, and $r$ is the number of the cointegrating vectors. Finally, $\Gamma_{i}$ are $p \times p$ matrices of coefficients while $\boldsymbol{\varepsilon}_{t}$ represents as usual the error term. The trace statistic is used to test whether temperature and radiative forcing cointegrate in a rolling window with fixed length. The use of a rolling window allows us to examine if and how the relationship evolves over time. The emphasis on cointegration forces us to choose a window in which both series are non-stationary. Based on this criterion and the results of the univariate analyses (Figs. 6.k and 6.l), we select a rolling window with 450 observations (section 3.1).

Stationary variables, such as volcanic forcing and El Nino events also affect surface temperatures. To include their effects, the distribution of the trace statistic is modified to account for nuisance parameters. Specifically, Rahbek and Mosconi (1999) (RM, hereafter) extend model (16) by including the accumulated sum of the $\mathrm{I}(0)$ variables ${ }^{21}$ and a time-trend. However, the presence of exogenous I(1) variables changes the limiting distribution of the trace statistic (Pesaran et al. 2000; Harbo et al. 1998). The extended $\mathrm{RM}$ model in error-correction form is:

$$
\Delta \mathbf{y}_{t}=\alpha\left(\beta^{\prime} \mathbf{y}_{t-1}+\beta_{z}^{\prime} \sum_{i=1}^{t} \mathbf{z}_{i}+\beta_{l}^{\prime} t\right)+\Phi \mathbf{z}_{t}+\sum_{i=1}^{k-1} \Gamma_{i} \Delta \mathbf{y}_{t-i}+\sum_{i=0}^{l-1} \Phi_{i} \Delta \mathbf{z}_{t-i}+\boldsymbol{\varepsilon}_{t}
$$

${ }^{21}$ Treating them as exogenous I(1) variables. 
in which, $\alpha, \beta, r, \Gamma_{i}$ and $\boldsymbol{\varepsilon}_{t}$ are as defined previously, $\mathbf{z}_{t}$ is $m$-dimensional stationary process, $\beta_{z}$ is $m \times r$ matrix, $\beta_{l}$ is $m$-dimensional vector, $\Phi_{i}$ is $p \times m$ matrix, and $t$ is a deterministic linear trend.

To evaluate the degree to which our results are sensitive to this methodology, we also estimate the long-run coefficients from a single equation cointegrating relation using the Fully-Modified Ordinary Least Squares (FM-OLS) method. The FM-OLS method uses a semi-parametric correction to circumvent difficulties caused by correlations between the cointegrating equation and the stochastic innovations (Phillips and Hansen, 1990).

\section{Results}

\subsection{Rolling unit-root testing}

The time series for temperature and radiative forcing evolve differently. Preliminary unitroot tests over the full sample (not presented here) indicate that the time series for temperature and solar insolation are $\mathrm{I}(1) .{ }^{22}$ Furthermore, the time series for stratospheric sulfates and the ENSO index are $\mathrm{I}(0) .{ }^{23}$ The same tests indicate that the time series for $\mathrm{CO}_{2}, \mathrm{CH}_{4}$ and $\mathrm{N}_{2} \mathrm{O}$ are $\mathrm{I}(2)$, while anthropogenic sulfur emissions are $\mathrm{I}(1) .{ }^{24}$ The finding that the radiative forcing of greenhouse gases is non-stationary is consistent with previous findings (e.g. Kaufmann et al., 2006a; 2013, and Stern and Kaufmann, 2000; 1999).

Given the presence of I(2) components (the forcings of greenhouse gases), one would expect that the aggregate forcing series also would be $\mathrm{I}(2)$. However, this assumption is realized only asymptotically or when the $\mathrm{I}(2)$ components dominate the

\footnotetext{
${ }^{22}$ When the same set of tests are used to evaluate the order of integration of the decycled and denoised temperature series and for the decycled solar forcing series, the results are the same.

${ }^{23}$ Results are available upon request.

${ }^{24}$ Kaufmann et al. (2013) provide the physical, biological, and economic justification for differences in the order of integration of time series for the components of the aggregate radiative forcing.
} 
aggregate. For the 1500-2011 sample period, the radiative forcing of greenhouse gases does not appear dominant. The radiative forcing of greenhouse gases increases by about $2.0 \mathrm{~W} / \mathrm{m}^{2}$ over the last 500 years. This rise is complemented by a $0.5 \mathrm{~W} / \mathrm{m}^{2}$ increase in the I(1) time series for the radiative forcing of solar insolation. Conversely, about 1 $\mathrm{W} / \mathrm{m}^{2}$ of this increase is offset by increases in anthropogenic sulfur emissions, which is I(1) (Stern and Kaufmann, 1999). In short, the time series for total radiative forcing is likely to appear I(1) because the I(2) trend associated with greenhouse gases is obfuscated by the I(1) trend associated with solar insolation and anthropogenic sulfur emissions.

The KSS test suggests that the stationarity properties of $T$ and $F$ change during the sample (Figs. 6.a to 6.l). This finding is robust across the six window lengths. For the $T$ series, the ratio of the KSS test statistic divided by the respective 0.05 critical value generally exceeds unity (indicating stationarity) at the start of the sample but falls below unity (indicating non-stationarity) towards the end of the sample. The KSS tests of the $F$ series show a similar pattern, but the change occurs earlier (see Figs. 6.a and 6.b). Essentially, the rolling estimates of the KSS statistic fall below the critical threshold with increasing frequency as the window length increases to incorporate more recent observations (in a sense non-stationarity dominates stationarity) and as the window rolls towards the end of the sample. Both of these changes allow the non-stationary components of the time series to dominate the stationary components. Indeed, nonstationarity becomes a dominant feature throughout the sample period for the window with 450 observations (see Figs. 6.k and 6.l). For this window length, $T$ and $F$ can be treated as I(1) processes. $^{25}$

\footnotetext{
25 Repeating the testing procedure using the raw data for temperature and aggregate forcing generates results that are similar to those in Figs. 6.a to 6.l. The series for raw temperature changes from I(0) to I(1) a few years later (possibly due to the presence of noise and cycles) for windows with 200, 250 and 300 observations. Similarly, the raw series for aggregate forcing changes from I(0) to I(1) a few years earlier (possibly due to the presence of cycles) for windows with 200 and 250 observations. These results are available upon request.
} 
Together, these results indicate that $T$ and $F$ are inconsistent with the proposition that the stationarity properties of the series remain constant throughout the sample (i.e. the radiative forcing of these gases is not disturbed during the sample period). As such, these changes can be interpreted as a first signal for a change in persistence, perhaps due to human activity.

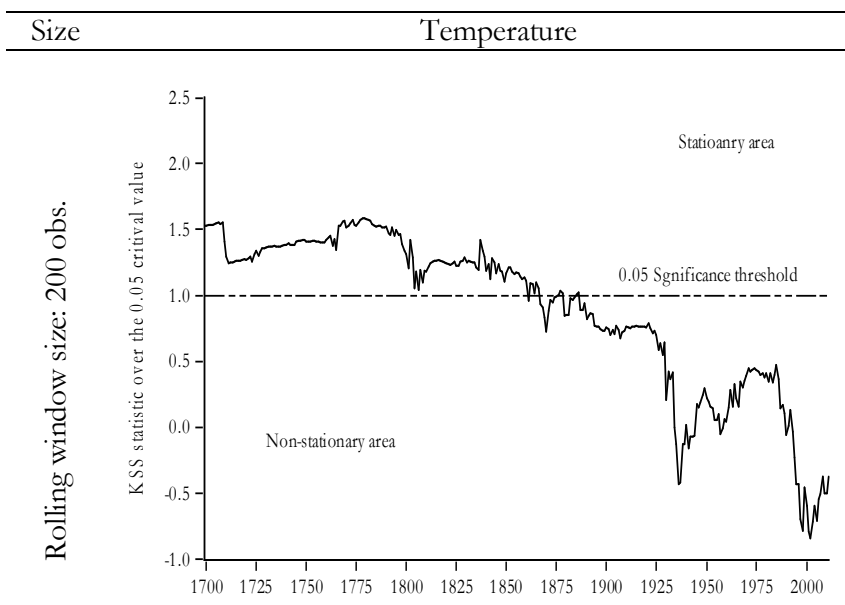

Fig. 6.a

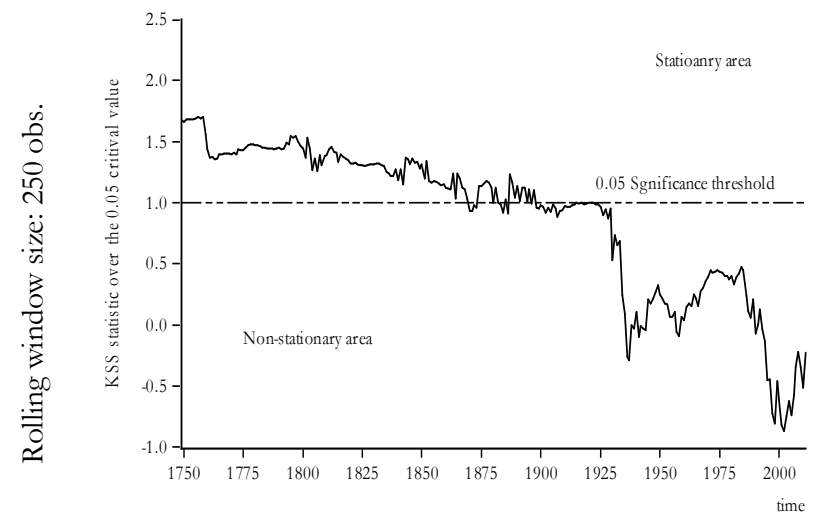

Fig. 6.c

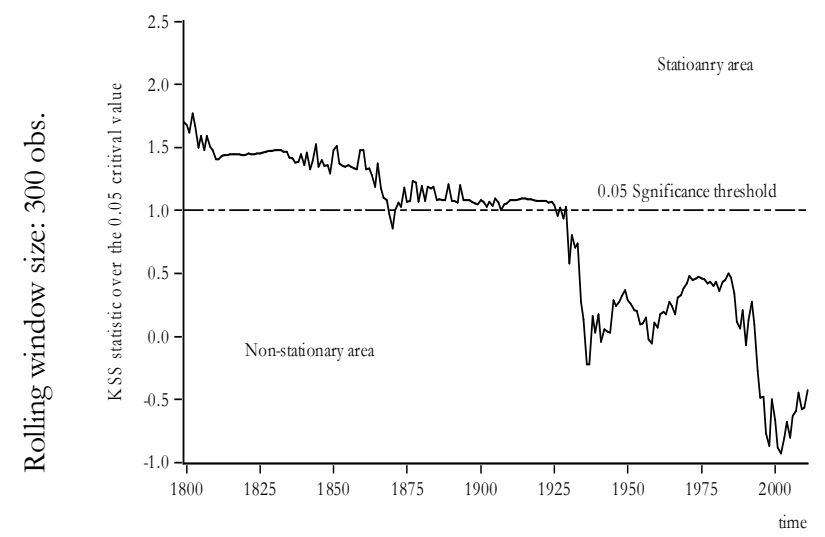

Fig. 6.e

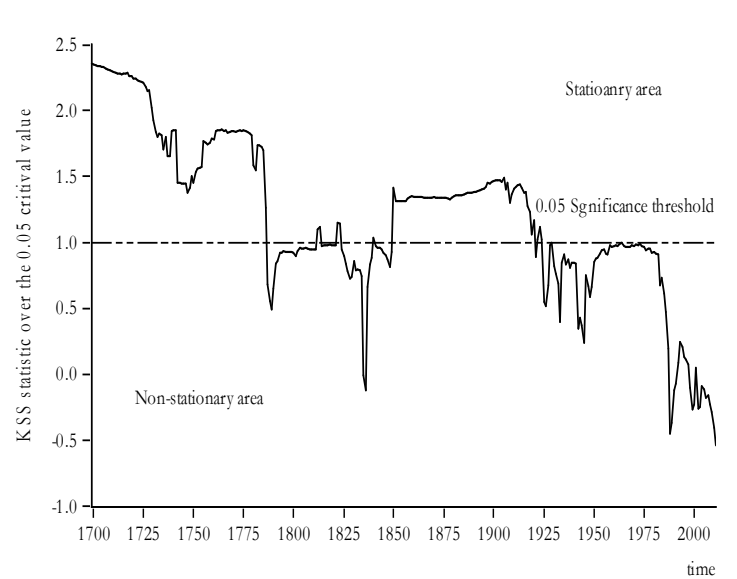

Fig. 6.b

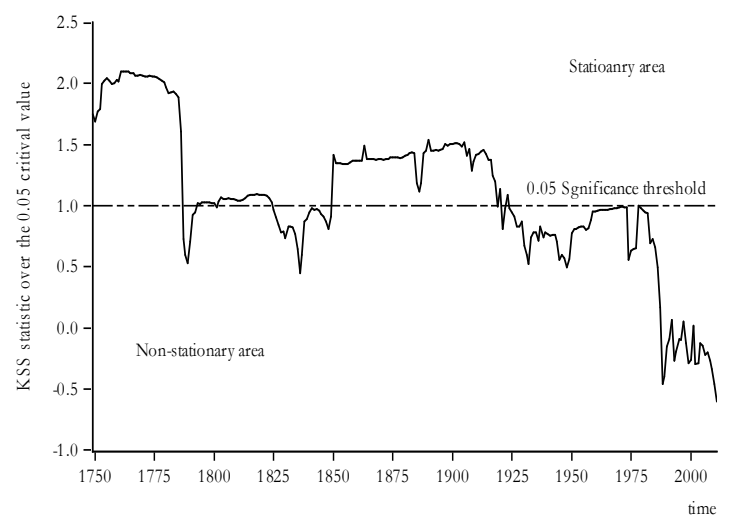

Fig. 6.d

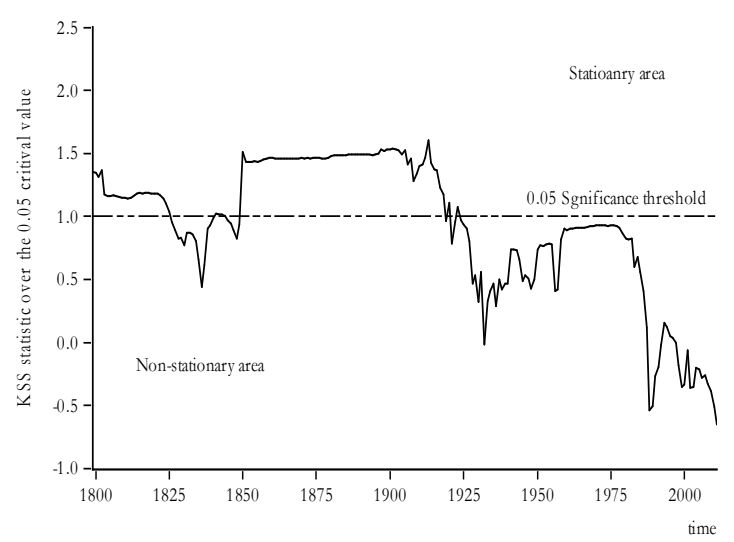

Fig. 6.f

Notes: see below 


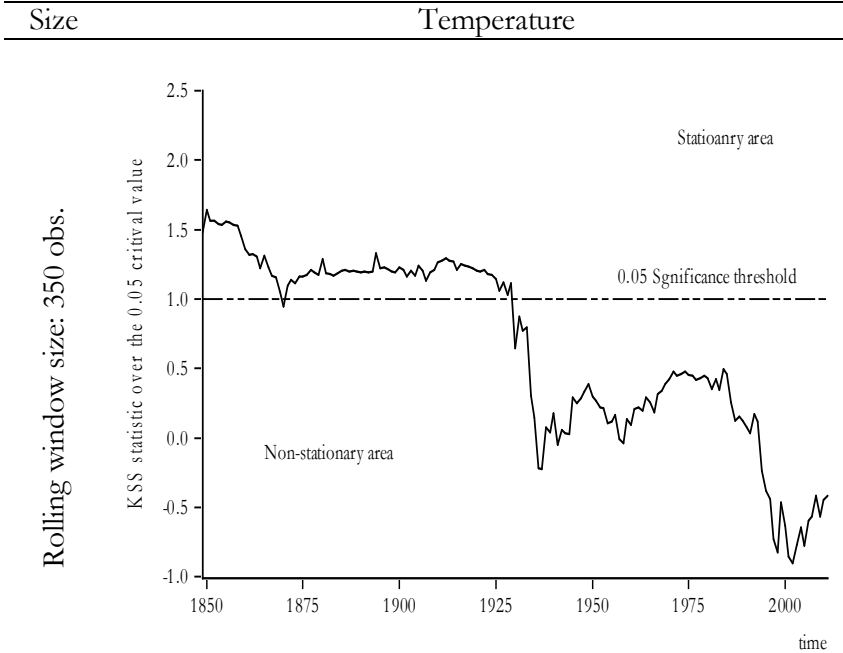

Fig. $6 . g$

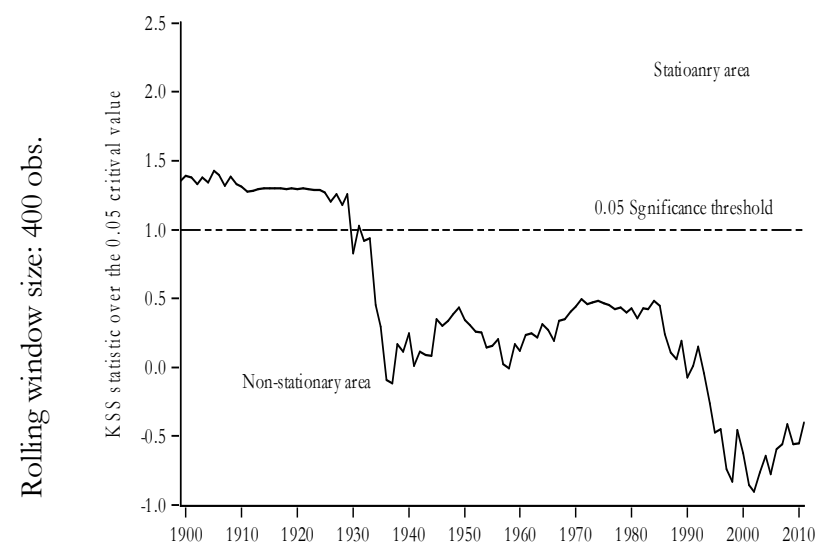

Fig. 6.i

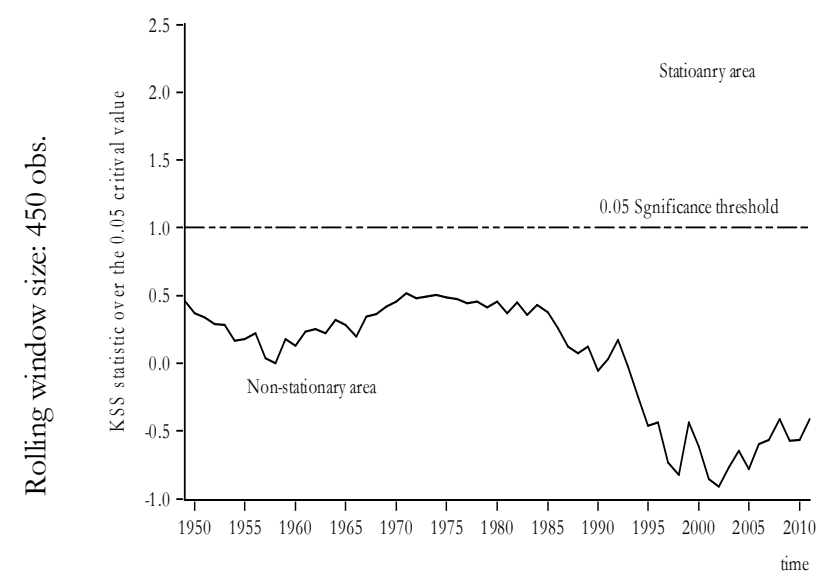

Fig. 6.k

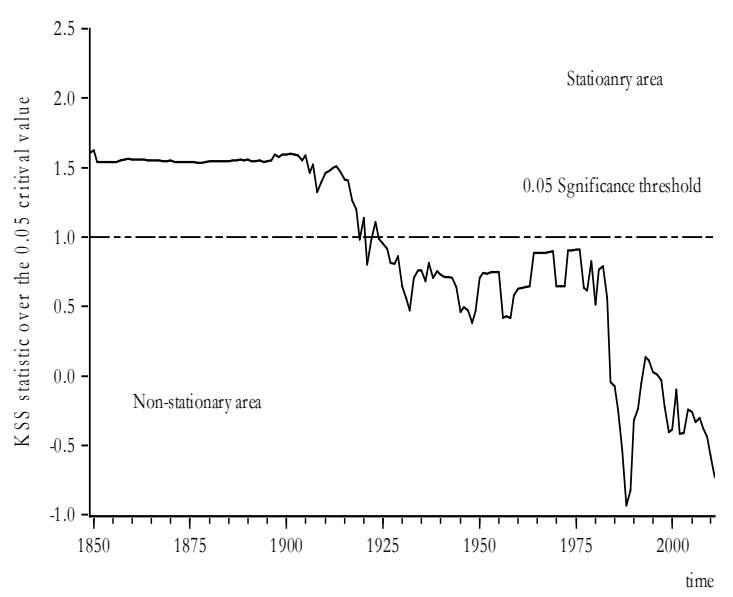

Fig. 6.h

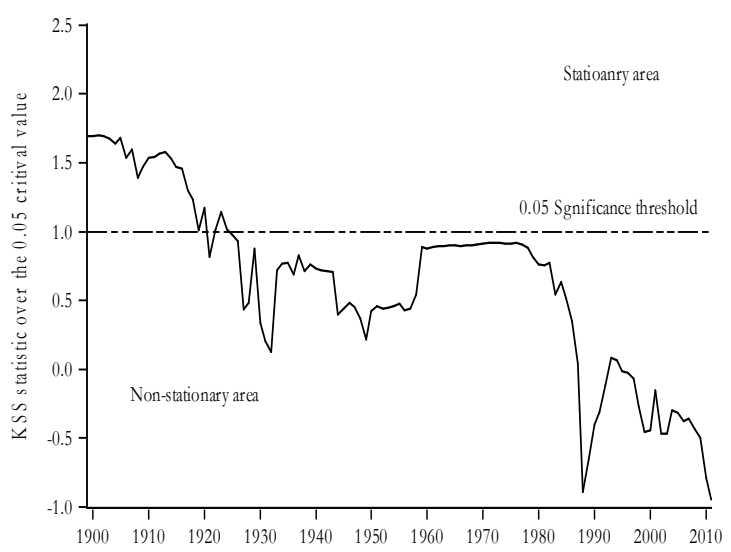

Fig. 6.j

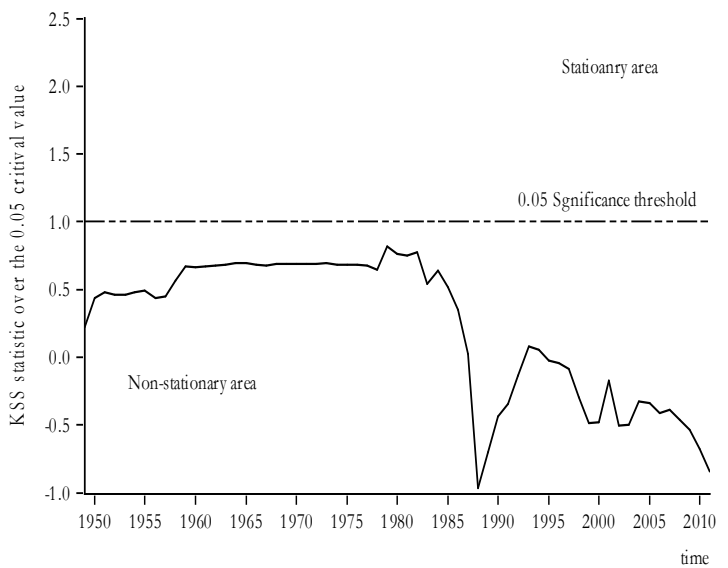

Fig. 6.l

Notes: KSS stands for the non-linear unit-root test proposed by Kapetanios et al. (2003). The presented $t_{N L}$ statistics (over the respective 0.05 critical value), for both series, are referred to the second case (for a stochastic with nonzero mean). Values above unity suggest stationarity, while values below unity suggest non-stationarity. In total, 2256 unit root tests have been conducted for both series in order to generate the above Figures (1128 tests for every series). 


\subsection{A change in persistence}

Having established that the stationarity properties do not remain constant, next we identify the date when the persistence changes. The B\&T test statistic provides strong evidence $(p$-value $<0.01)$ that the time series of $F$ and $T$ change from $\mathrm{I}(0)$ to $\mathrm{I}(1)$ in 1784 and 1862, respectively (Table 1). This conclusion is reinforced by the HL\&T test statistic (Table 2). Together, the modified tests for a change in persistence indicate that the time series for $F$ changes $(p$-value $<0.01)$ from $\mathrm{I}(0)$ to $\mathrm{I}(1)$ during the fourth quarter of the $18^{\text {th }}$ century, while the time series for $T$ changes ( $p$-value $\left.<0.01\right)$ from $\mathrm{I}(0)$ to $\mathrm{I}(1)$ in the third quarter of the $19^{\text {th }}$ century. ${ }^{26}$

Table 1. B\&T test for a change in persistence.

\begin{tabular}{|c|c|c|c|c|c|}
\hline \multirow[t]{2}{*}{ Test Statistic } & \multirow[t]{2}{*}{ Direction } & $\begin{array}{c}\text { Statistic's value } \\
m=0 \text { to } m=12\end{array}$ & 0.1 critical value & 0.05 critical value & 0.01 critical value \\
\hline & & \multicolumn{4}{|c|}{ B\&T testing for $T$. Identified break date: 1862} \\
\hline$H_{1}\left(\mathscr{K}_{M}().\right)$ & \multirow{3}{*}{$\mathrm{I}(0) \rightarrow \mathrm{I}(1)$} & $638.966 * * *$ & 13.630 & 18.163 & 29.890 \\
\hline$H_{2}\left(\mathscr{K}_{M}().\right)$ & & $208.118^{* * *}$ & 3.486 & 4.611 & 7.507 \\
\hline$H_{3}\left(\mathscr{K}_{M}().\right)$ & & $313.836^{* * *}$ & 3.328 & 5.128 & 10.526 \\
\hline$H_{1}\left(1 / \mathscr{K}_{M}().\right)$ & \multirow{3}{*}{$\mathrm{I}(1) \rightarrow \mathrm{I}(0)$} & 0.059 & 13.630 & 18.163 & 29.890 \\
\hline$H_{2}\left(1 / \mathscr{M}_{M}().\right)$ & & 0.008 & 3.486 & 4.611 & 7.507 \\
\hline \multirow[t]{2}{*}{$H_{3}\left(1 / \mathscr{K}_{M}().\right)$} & & 0.004 & 3.328 & 5.128 & 10.526 \\
\hline & \multicolumn{5}{|c|}{ B\&T testing for $F$. Identified break date: 1784} \\
\hline$H_{1}\left(\mathscr{K}_{M}().\right)$ & \multirow{3}{*}{$\mathrm{I}(0) \rightarrow \mathrm{I}(1)$} & $856.914 * * *$ & 13.630 & 18.163 & 29.890 \\
\hline$H_{2}\left(\mathscr{K}_{M}().\right)$ & & $278.964 * * *$ & 3.486 & 4.611 & 7.507 \\
\hline$H_{3}\left(\mathscr{K}_{M}().\right)$ & & $423.722^{* * *}$ & 3.328 & 5.128 & 10.526 \\
\hline$H_{1}\left(1 / \mathscr{K}_{M}().\right)$ & \multirow{3}{*}{$\mathrm{I}(1) \rightarrow \mathrm{I}(0)$} & 0.101 & 13.630 & 18.163 & 29.890 \\
\hline$H_{2}\left(1 / \mathscr{M}_{M}().\right)$ & & 0.016 & 3.486 & 4.611 & 7.507 \\
\hline$H_{3}\left(1 / \mathscr{K}_{M}().\right)$ & & 0.008 & 3.328 & 5.128 & 10.526 \\
\hline
\end{tabular}

Notes: $* * *, * *$ and $*$ denote significance at the $0.01,0.05$ and 0.1 significance level, respectively. The critical values reported come from Busetti and Taylor (2004). The search interval for the break is $[0.2,0.8]$.

\footnotetext{
${ }^{26}$ Subjecting the raw data to both tests (B\&T and HL\&T) provide strong evidence that temperature and aggregate forcing change from $\mathrm{I}(0)$ to $\mathrm{I}(1)$ in 1898 and 1725, respectively. As such, the results are qualitatively similar to those presented in Tables 1 and 2 . The only difference concerns the identified break dates. For the raw temperature series, the change takes place few years later (possibly due to the presence of noise and cycles), while for the raw aggregate forcing series, the change takes place few years earlier (possibly due to the presence of cycles). These results are available upon request.
} 
Table 2. HL\&T test for a change in persistence.

\begin{tabular}{|c|c|c|c|c|c|}
\hline \multirow[t]{2}{*}{ Test Statistic } & \multirow[t]{2}{*}{ Direction } & $\begin{array}{c}\text { Statistic's value } \\
m=0 \text { to } m=12\end{array}$ & 0.1 critical value & 0.05 critical value & 0.01 critical value \\
\hline & & \multicolumn{4}{|c|}{ HL\&T testing for $T$. Identified break date: 1862} \\
\hline$H_{1}\left(\mathscr{Y}_{M}().\right)$ & \multirow{3}{*}{$\mathrm{I}(0) \rightarrow \mathrm{I}(1)$} & $575.726 * * *$ & 13.420 & 17.800 & 29.750 \\
\hline$H_{2}\left(\mathscr{K}_{M}().\right)$ & & $191.156^{* * *}$ & 3.510 & 4.600 & 7.520 \\
\hline$H_{3}\left(\mathscr{K}_{M}(\cdot)\right)$ & & $279.611 * * *$ & 3.350 & 5.120 & 10.37 \\
\hline$H_{1}\left(1 / \mathscr{K}_{M}().\right)$ & \multirow{3}{*}{$\mathrm{I}(1) \rightarrow \mathrm{I}(0)$} & 0.000 & 13.70 & 17.850 & 29.360 \\
\hline$H_{2}\left(1 / \mathscr{K}_{M}().\right)$ & & 0.000 & 3.530 & 4.600 & 7.420 \\
\hline \multirow[t]{2}{*}{$H_{3}\left(1 / \mathscr{K}_{M}().\right)$} & & 0.000 & 3.460 & 5.110 & 10.290 \\
\hline & \multicolumn{5}{|c|}{ HL\&T testing for $F$. Identified break date: 1784} \\
\hline$H_{1}\left(\mathscr{Y}_{M}().\right)$ & \multirow{3}{*}{$\mathrm{I}(0) \rightarrow \mathrm{I}(1)$} & $772.103 * * *$ & 13.420 & 17.800 & 29.750 \\
\hline$H_{2}\left(\mathscr{K}_{M}().\right)$ & & $256.227 * * *$ & 3.510 & 4.600 & 7.520 \\
\hline$H_{3}\left(\mathscr{K}_{M}().\right)$ & & $377.514 * * *$ & 3.350 & 5.120 & 10.37 \\
\hline$H_{1}\left(1 / \mathscr{K}_{M}().\right)$ & \multirow{3}{*}{$\mathrm{I}(1) \rightarrow \mathrm{I}(0)$} & 0.000 & 13.70 & 17.850 & 29.360 \\
\hline$H_{2}\left(1 / \mathscr{K}_{M}().\right)$ & & 0.000 & 3.530 & 4.600 & 7.420 \\
\hline$H_{3}\left(1 / \mathscr{K}_{M}(\cdot)\right)$ & & 0.000 & 3.460 & 5.110 & 10.290 \\
\hline
\end{tabular}

Notes: $* * *, * *$ and $*$ denote significance at the $0.01,0.05$ and 0.1 significance level, respectively. The break dates are the same as those indicated in Table 2. The critical values presented come from Harvey et al. (2006) for $n=500$, where $n$ is the sample size. The search interval for the break is $[0.2,0.8]$.

\subsection{Cointegration analysis}

The order of integration indicated by the preceding tests implies that there could be a long-run relationship between temperature and aggregate radiative forcing. For each rolling window, the trace statistic rejects $(p<0.05)$ the null hypothesis of zero cointegrating relations; this allows us to accept the alternative hypothesis of a single cointegrating relation. These results are consistent with the hypothesis that there is a systematic long-run relationship between aggregate radiative forcing and temperature during the periods that are covered by the 450 year rolling windows. Furthermore, all of the long-run coefficients ${ }^{27}$ are statistically different from zero $(p<0.05)$ and are stable over time (Fig. 7). These results do not change if the bivariate model is estimated using the single equation FM-OLS technique (Fig. 7).

\footnotetext{
27 The estimated cointegrating vectors have been normalized on $T$. The signs of the long-run coefficients have been reversed after the normalization process.
} 


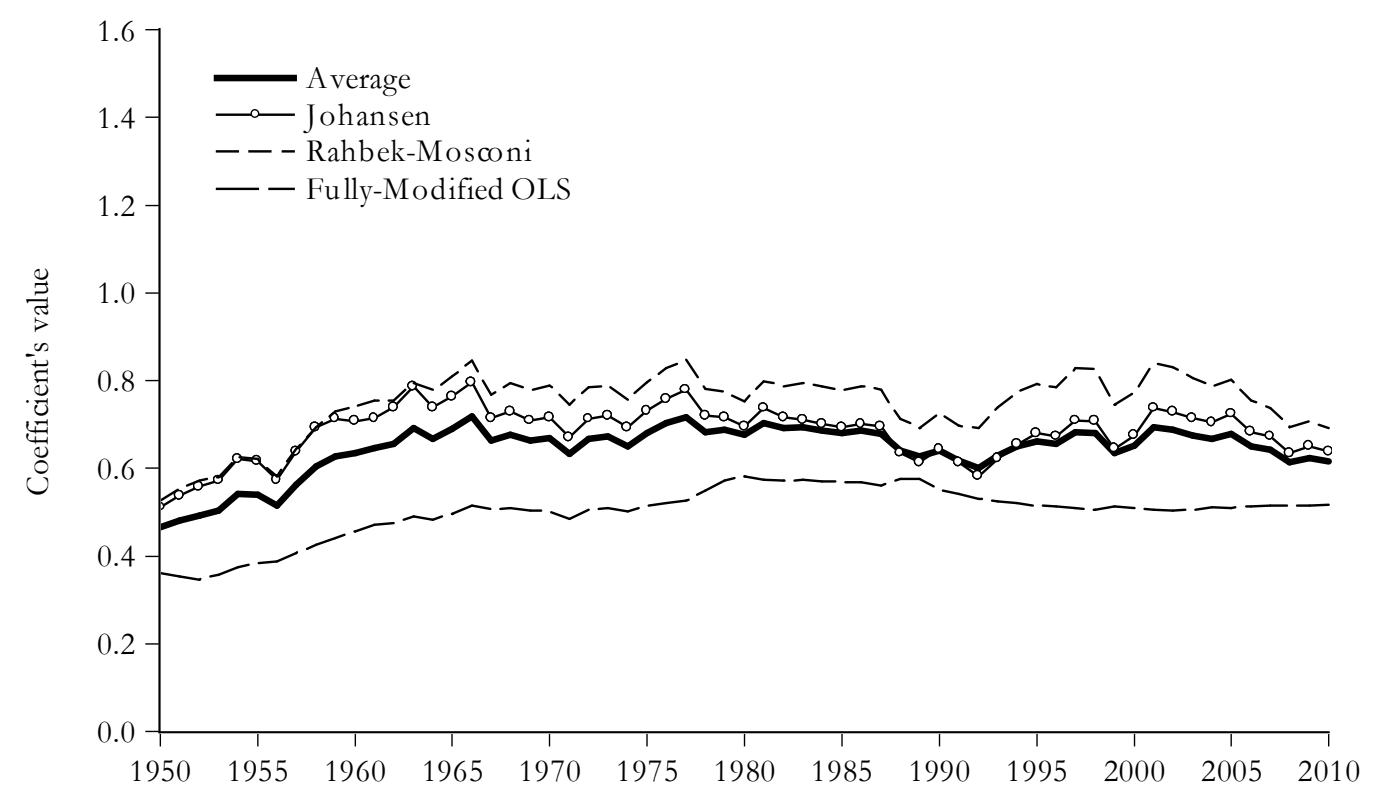

Fig. 7. Point estimates for the long-run relation between radiative forcing and temperature for rolling windows that end in the date shown and estimated using three statistical techniques.

Next, we include two stationary variables (volcanic forcing and the ENSO index) in the model of surface temperature (Rahbek and Mocsoni, 1999). Consistent with the results generated by the Johansen cointegration approach, the corrected trace statistic is statistically significant $(\phi<0.05)$ for each rolling window. This implies that radiative forcing cointegrates with temperature even when we account for the effects of volcanic eruptions (the radiative forcing of stratospheric sulfates) and changes in oceanic/atmospheric circulation (the ENSO index). Furthermore, the evolution of the long-run coefficients (Fig. 7) and their statistical significance are qualitatively similar to the findings generated by the methods used above. ${ }^{28}$

Together, the three techniques implemented here generate results that indicate; (1) the statistical significance and magnitude of the long-run relation between radiative

\footnotetext{
28 Applying these same three cointegration techniques to the raw data, for the same rolling window (450 observations), we find a systematic long-run relationship between temperature and aggregate forcing. But the long-run coefficient increases with time, which is inconsistent with the notion of cointegration. As such, the denoised and decycled data allow the statistical methodology to qualify the long-run relation more accurately. These results are available upon request.
} 
forcing and temperature remains relatively constant $\mathrm{t}^{29}$ over time and (2) these results are robust with regard to the statistical methodology. Furthermore, the size of the long-run coefficient and/or the precision of its measure are not affected qualitatively by including two stationary variables; the radiative forcing of volcanic aerosols (stratospheric sulfates) and the index for the Southern Oscillation.

\section{Discussion}

The totality of statistical results described above is consistent with the two hypotheses described in Section 1. This consistency would seem to contradict Ruddiman (2003), who argues that human activities started to affect climate about eight thousand years ago. This hypothesis is undermined by recent analyses, which indicate that anthropogenic land-use change is not needed to account for the rise in atmospheric methane over the last 5,000 years (Singarayer et al., 2011) and is not consistent with the isotopic make-up of atmospheric carbon dioxide concentrations during the previous 11,000 years (Elsig et al., 2009). Consistent with these results, Kaufmann and Juselius (2013) find that orbital changes can account for all persistent changes in carbon dioxide, methane, and surface temperature during the previous 391 thousand years.

With regard to the first hypothesis, the change in the time series properties and/or persistence is consistent with the notion that humans are becoming an increasingly important actor in global biogeochemical cycles, and that these disruptions affect the persistence of radiative forcing. The lag between the change in persistence of $F$ and $T$ is consistent with the anthropogenic theory of climate change. According to this theory, human emissions affect radiative forcing, which generates a change in temperature. As

\footnotetext{
${ }^{29}$ The mean value of the long-run coefficients that have been estimated by the three different approaches is equal to 0.643 .
} 
such, $F$ is expected to change before $T$. Conversely, a change in the persistence of temperature that precedes a change in the persistence of atmospheric carbon dioxide would imply that human activities are not responsible for elevated levels of $\mathrm{CO}_{2}$ and/or the relation between anthropogenic emissions, elevated concentrations, and higher temperatures is simply a correlation. Although we cannot reject this correlation using our statistical method, here we describe observations that support a causal relation from human activity to radiative forcing.

Furthermore, the relatively long lag between the change in persistence of $F$ and $T$ is consistent with the importance of internal climate variability. When the time series for radiative forcing changes from $\mathrm{I}(0)$ to $\mathrm{I}(1)$ in fourth quarter of the $18^{\text {th }}$ century, its value is barely different from zero. Such a small change generates an even smaller change in temperature and therefore the effect of a change in radaitive forcing would be difficult to detect against the natural variability in temperature. By 1900, radiative forcing reaches 0.5 $\mathrm{W} / \mathrm{m}^{2}$. This implies a long-run temperature increase of about $0.35^{\circ} \mathrm{C}$ (based on the point estimates for the long-run relation between temperature and radiative forcing in Fig. 7). Such a rise is comparable to the natural variability in temperature, which enables detection.

Although our methodological framework does not explicitly identify the way in which the Industrial Revolution changes the persistence of radiative forcing and so is moot regarding causality, causal mechanisms can be postulated based on first principles by examining the link from human actions to emissions and the link from emissions to radiative forcing. Anthropogenic emissions of greenhouse gases (and sulfur aerosols) are driven by population growth and economic activity. Both activities are changed by the Industrial Revolution and these changes alter the persistence of anthropogenic emissions. Furthermore, increases in concentrations (caused by anthropogenic emissions) can 
change the atmospheric lifetime of gases, which affects the persistence of their radiative forcing by changing the way that the atmosphere integrates emissions.

The effect of changes in population growth and economic activity on anthropogenic emissions and the persistence of the aggregate for radiative forcing can be illustrated by changes in anthropogenic emissions of carbon dioxide. Deforestation is the largest source of anthropogenic carbon emissions before 1934 (Boden et al., 2010; Houghton, 1999), which makes up the majority of the five hundred year sample period. Deforestation is driven largely by the need to grow more food to feed an expanding human population (Lambin and Meyfroidt, 2011). As such, the quantity of carbon emitted is small relative to the quantity in the atmosphere. For example the radiative forcing of carbon dioxide in 1934 is $0.70 \mathrm{~W} / \mathrm{m}^{2}$ compared to $0.16 \mathrm{~W} / \mathrm{m}^{2}$ in 1500 (Fig. 1). Furthermore, the increase in atmospheric carbon dioxide due to deforestation can be relatively short-lived (compared to fossil fuel emissions) because forests remove carbon dioxide from the atmosphere as forests regrow.

After 1934, the majority of anthropogenic carbon emissions are caused by the combustion of fossil fuels (Boden et al., 2010; Houghton, 1999). Statistical analyses of energy use indicate that carbon emissions are closely related to population growth and economic activity (e.g. Waggoner and Ausubel, 2002). And economic activity, as measured by GDP, is widely thought to contain a stochastic trend (Nelson and Plosser, 1982; West, 1988; King et al., 1991). Since the Industrial Revolution, economic activity increases faster than population such that per capita income (and energy use and carbon emissions) generally increases over time. From a time series perspective, the mean value of the innovations in the DGP for anthropogenic carbon emissions due to energy use is greater than the mean value for the innovations in the DGP for carbon emissions due to deforestation. The increasing importance of the stochastic trend associated with fossil fuel consumption is largely responsible for the increase in radiative forcing due to $\mathrm{CO}_{2}$ 
from $0.70 \mathrm{~W} / \mathrm{m}^{2}$ in 1934 to $2.21 \mathrm{~W} / \mathrm{m}^{2}$ in 2011 (Fig. 1). Furthermore, this source of emissions probably increases in the persistence of atmospheric carbon dioxide. The carbon emitted by burning fossil fuels flows back to the fossil fuel storage at rates that are measured on geological time scales as opposed to carbon that is emitted by deforestation, much of which can flow back to growing forests within a century.

The change in the persistence of the aggregate for radiative forcing also may be caused by changes in the atmospheric lifetime of individual gases due to increasing concentrations that are generated by the Industrial Revolution. The atmospheric lifetime of a gas is defined by the period it takes for a perturbation to be reduced to 37 percent of its initial amount (Meehl and Stocker, 2007). The atmospheric lifetime of methane generally is thought to be about twelve years (Prather et al., 2001). This implies a decay rate that would generate a near unit root process. But the atmospheric lifetime of methane is not constant. Methane is removed from the atmosphere by the hydroxyl radical $(\mathrm{OH})$. Several studies suggest that global levels of $\mathrm{OH}$ decline over the industrial era (Lelieveld et al., 1998; Wang and Jacob, 1998; Houweling et al. 2000). If this decline is correct, reductions in $\mathrm{OH}$ concentrations would elongate the atmospheric lifetime of methane (Prather, 1994). Consistent with this notion, isotopic analyses suggest a sudden (between 1905 and 1910) increase in the atmospheric lifetime of methane that continues through to 1980 (Lassey et al., 2007). Such a change could alter the persistence of the time series for the radiative forcing of methane.

The finding that the time series for radiative forcing and temperature share the same stochastic trend implies that there is a statistically meaningful long-run relation between global surface temperature and radiative forcing (Kaufmann et al., 2006a; Kaufmann et al., 2011; Kaufmann et al., 2013). Analyses of global temperature simulated by climate models (with known values of transient climate sensitivity and equilibrium temperature response) indicate that the cointegrating relation between radiative forcing and 
temperature represents the transient climate response (Kaufmann et al., 2006b), which is defined as the temperature change observed at the time that the atmospheric concentration of $\mathrm{CO}_{2}$ doubles and integrates all processes operating in the system, including the strength of the feedback and the rate of heat storage in the ocean (Cubasch and Meehl, 2001). Estimates for the transient climate response generated by our statistical methodology vary from $2.18^{\circ} \pm 1.06^{\circ} \mathrm{C},{ }^{30}$ which is the value implied by the average value of the coefficient generated by the FM-OLS estimator, to $3.0^{\circ} \pm 1.14^{\circ} \mathrm{C}$, which is the average generated by the Johansen procedure, to $3.26^{\circ} \pm 1.16^{\circ} \mathrm{C}$, which is the average generated by the $\mathrm{RM}$ procedure. This range expands to $1.5 \pm 1.08^{\circ} \mathrm{C}$ to $3.5 \pm 1.47^{\circ} \mathrm{C}$ if we choose the minimum and maximum values for any subsample as estimated by any of the three statistical methods. This range is consistent with that reported by the IPCC, which states with high confidence that the transient climate response lies between $1^{\circ} \mathrm{C}$ and $2.5^{\circ} \mathrm{C}$ and is extremely unlikely to be greater than $3.0^{\circ} \mathrm{C}$ (Bindoff et al., 2013).

Again, the presence of a cointegrating relation between radiative forcing and temperature (and the estimate for its transient climate response) does not establish a causal relation from human activity and temperature. Indeed, Kaufmann and Juselius (2013) find a cointegrating relation between atmospheric $\mathrm{CO}_{2}$ and Antarctic surface temperature during the previous 391 thousand years, when human activity has no measurable effect on atmospheric concentrations of carbon dioxide.

Nonetheless, we postulate that the cointegrating relation between radiative forcing and surface temperature links human activity to climate based on evidence for the effects of human activity on the atmospheric concentration of radiatively active gases. These effects are established by changes in the isotopic signature of greenhouse gases in the

\footnotetext{
30 The transient climate response is calculated by multiplying the coefficient for the long-run relation between radiative forcing and temperature by $6.3 * \ln (2)$ (Kaufmann et al., 2006a).
} 
atmosphere. Because fossil fuels have been sequestered below ground for millions of years, the carbon that is emitted by the combustion of fossil fuels has little ${ }^{14} \mathrm{C}$ (an isotope of carbon). As such, the carbon that accumulates in the atmosphere due to the combustion of fossil fuels can account for the decline in the ratio of ${ }^{14} \mathrm{C}$ to ${ }^{12} \mathrm{C}$ (the usual isotope of carbon) in the atmosphere and tree rings (Cais et al., 2013). Similarly, the combustion of fossil fuels and deforestation emits carbon that has a lower ratio of ${ }^{13} \mathrm{C}$ to ${ }^{12} \mathrm{C}$, and therefore reduces this ratio in the atmosphere. This reduction is documented by isotopic analyses of atmospheric carbon dioxide (Cais et al., 2013). Together, these isotopic changes provide strong observational evidence that human activities affect the atmospheric concentration of radiatively active gases, which is consistent with the hypothesis that the cointegrating relation between radiative forcing and temperature transmits the effect of human activity to climate.

\section{Conclusions}

Our results extend previous analyses by expanding the sample to include data that spans five centuries. This expansion is critical because it provides a new way to evaluate the hypothesis of anthropogenic climate change. Put simply, expanding the sample allows us to compare two periods of human activity; (1) prior to the Industrial Revolution, when humans are thought to have had little effect on biogeochemical cycles and climate and (2) after the Industrial Revolution, when human actions are thought to have had a measurable impact on biogeochemical cycles and climate.

This before-and-after comparison is based on the notion that the Industrial Revolution changes the way that humans interact with global biogeochemical cycles. Prior to the Industrial Revolution, humans probably had little impact on climate because they had relatively little effect on the storages and flows in the global biogeochemical 
cycles of carbon, nitrogen, and sulfur. These effects change in type and magnitude after the Industrial Revolution. The Haber Bosch process now fixes more nitrogen than the biota (Cais et al., 2013), and this affects atmospheric concentrations of $\mathrm{N}_{2} \mathrm{O}$. As described above, the consumption of fossil fuels is largely responsible for pushing the atmospheric concentration of carbon dioxide to $400 \mathrm{ppm}$ and beyond, which is the highest level in more than one million years (Gillis, 2013).

Although our before and after comparison does not allow us to test causal mechanisms, the results indicate that the persistence of radiative forcing and temperature has changed over the last 500 years and that this change creates an I(1) fingerprint in radiative forcing (that includes human activities) that can be detected in a statistically measureable fashion in surface temperature. As such, our results are consistent with the physical mechanisms that underlie the theory of anthropogenic climate change.

\section{References}

Ammann, C.M. and E.R. Wahl (2007). The importance of the geophysical context in statistical evaluations of climate reconstruction procedures. Climatic Change 85, 7188.

Bindoff, N.L., P.A. Stott, K.M. AchutaRao, M.R. Allen, N. Gillett, D. Gutzler, K. Hansingo, G. Hegerl, Y. Hu, S. Jain, I.I. Mokhov, J. Overland, J. Perlwitz, R. Sebbari and X. Zhang (2013). Detection and Attribution of Climate Change: from Global to Regional. In: Climate Change 2013: The Physical Science Basis. Contribution of Working Group I to the Fifth Assessment Report of the Intergovernmental Panel on Climate Change. Edited by Stocker TF, Qin D, Plattner G-K, Tignor M, Allen SK, Boschung J, Nauels A, Xia Y, Bex V and Midgley PM. Cambridge University Press, Cambridge, United Kingdom and New York, NY, USA.

Bloomfield, P. and D. Nychka (1992). Climate Spectra and Detecting Climate Change. Climatic Change 21, 275-287.

Boden, T.A., G. Marland and R.J. Andres (2010). Global, regional, and national fossilfuel $\mathrm{CO}_{2}$ emissions. Carbon Dioxide Information Analysis Center, Oak Ridge National Laboratory, U.S. Department of Energy, Oak Ridge, Tenn., U.S.A.. 
Brock, W.A., J.A. Scheinkman, W.D. Dechert and B. LeBaron (1996). A test for independence based on the correlation dimension. Econometric Reviews 15, 197-235.

Busetti, F. and A.M.R. Taylor (2004). Tests of stationarity against a change in persistence. Journal of Econometrics 123, 33-66.

Ciais P, Sabine C, Bala G, Bopp L, Brovkin V, Canadell J, Chhabra A, DeFries R, Galloway J, Heimann M, et al. (2013). Carbon and Other Biogeochemical Cycles. In: Climate Change 2013: The Physical Science Basis. Contribution of Working Group I to the Fifth Assessment Report of the Intergovernmental Panel on Climate Change. Edited by Stocker TF, Qin D, Plattner G-K, Tignor M, Allen SK, Boschung J, Nauels A, Xia $\mathrm{Y}$, Bex V and Midgley PM. Cambridge University Press, Cambridge, United Kingdom and New York, NY, USA: 465-570.

Cubasch. U. and G.A. Meehl (2001). Projections of future climate change. In Climate Change 2001: The scientific basis. Contribution of working group I of the third assessment report of the Intergovernmental Panel on Climate Change. Cambridge University Press, 526-582.

Elsig, J., J. Schmitt, D. Leuenberger, R. Schneider, M. Eyer, M. Leuenberger, F. Joos, H. Fischer, and T.F. Stocker (2009). Stable isotope constraints on Holocene carbon cycle changes from an Antarctic ice core. Nature 461, 507-510.

Enders, W. (1995). Applied Econometric Time Series, Wiley, New York.

Gay, C., F. Estrada and A. Sanchez (2009). Global and hemispheric temperature revisited. Climatic Change 94, 333-349.

Gillis, J. (2013). Heat-trapping gas passes milestone, raising fears. New York. Times. May, 13.

Goosse H., T.J. Growley, E. Zorita, C.M. Amman, H. Renssen and E. Driesschaert (2005). Modelling the climate of the last millennium: What causes the differences between simulations? Geophysical Research Letters 32(6), 1-4.

Hamilton, J. D. (1994). Time Series Analysis, Princeton University Press, Princeton, NJ.

Harbo, I., S. Johansen, B. Nielsen and A. Rahbek (1998). Asymptotic inference on cointegration rank in partial systems. Journal of Business and Economic Statistics 16, 388399.

Harvey, D.I., S.J. Leybourne and A.M.R. Taylor (2006). Modified tests for a change in persistence. Journal of Econometrics 134, 441-469.

Hendry, D. and Juselius, K. (2000). Explaining cointegration analysis: Part 1. Energy Journal 21, 1-24.

Houghton R.A. (1999). The annual net flux of carbon to the atmosphere from changes in the land-use 1850-2005. Tellus 51, 298-313.

Houweling, S., F.J. Dentener, J. Lelieveld, B. Walter and E.J. Dlugo-kencky (2000). The modeling of tropospheric methane: How well can point measurements be reproduced by a global model? Journal of Geophysical Research 105, 8981-9002. 
Johansen, S. (1995). Likelihood-Based Inference in Cointegrated Vector Autoregressive Models, Oxford University Press, Oxford.

Kapetanios, G., Y. Shin and A. Snell (2003). Testing for a Unit Root in the Nonlinear STAR Framework. Journal of Econometrics 112, 359-379.

Kaufmann, R. and K. Juselius (2013). Testing Hypotheses about Glacial Cycles against the Observational Record. Paleoceanography 28, 175-184.

Kaufmann, R.K., H. Kauppi, M.L. Mann and J.H. Stock (2013). Does temperature contain a stochastic trend: linking statistical results to physical mechanisms. Climatic Change 118, 729-743.

Kaufmann R.K., H. Kauppi, M.L. Mann and J.H. Stock (2011). Reconciling anthropogenic climate change with observed temperature 1998-2008. Proceedings of the National Academy of Sciences of the United States 108, 11790-11793.

Kaufmann, R.K., H. Kauppi and J.H. Stock (2006a). Emissions, Concentrations and Temperature: A Time Series Analysis. Climatic Change 77, 249-278.

Kaufmann, R.K., H. Kauppi and J.H. Stock (2006b). The Relationship between Radiative Forcing and Temperature: What Do Statistical Analyses of the Instrumental Temperature Record Measure? Climatic Change 77, 279-289.

Kaufmann, R.K., H. Kauppi and J.H. Stock (2010). Does Temperature Contain a Stochastic Trend? Evaluating Conflicting Statistical Results. Climatic Change 101, 395-405.

Kaufmann, R.K. and D.I. Stern (2002). Cointegration Analysis of Hemispheric Temperature Relations. Journal of Geophysical Research 107, ACL 8.1-8.10.

King R.G., C.I. Plosser, J.H. Stock and M.W. Watson (1991). Stochastic trends and economic fluctuations. American Economic Review 81, 819-840.

Kim, K. and P. Schmidt (1990). Some evidence on the accuracy of Phillips-Perron tests using alternative estimates of nuisance parameters. Economics Letters 34, 345-350.

Lambin, E.F. and P. Meyfroidt (2011). Global land use change, economic globalization, and the looming land scarcity. Proceedings National Academy of Sciences 100, 3465-3472.

Lassey KR, D.C. Lowe and A.M. Smith (2007). The atmospheric cycling of radiomethane and the "fossil fraction" of the methane source. Atmospheric Chemistry and Physics 7, 2141-2149.

Lelieveld, J., P.J Crutzen and F.J. Dentener (1998). Changing concentration, lifetime and climate forcing of atmospheric methane. Tellus B 50, 128-150.

Li, J., S.P. Xie, E.R. Cook, G. Huang, R. D'Arrigo, F. Liu and J. Ma (2011). Interdecadal modulation of El Niño amplitude during the past millennium. Nature Climate Change $1,114-118$. 
Meehl, G.A. and T.F. Stocker (2007). Global climate projections, in Solomon, S., et al., eds., Climate Change 2007: The Physical Science Basis, Cambridge University Press, Cambridge, UK, 747-845.

Mursula, K., I.G. Usoskin and G.A. Kovaltsov (2001). Persistent 22-year cycle in sunspot activity: Evidence for a relic solar magnetic field. Solar Physics 198, 51-56.

Nelson, C.R. and C.I. Plosser (1982). Trends and random walks in macroeconomic time series: some evidence and implications. Journal of Monetary Economics 10, 139-162.

Ogurtsov, M.G., Y.A. Nagovitsyn, G.E. Kocharov, and H. Jungner (2002). Long-period cycles of Sun's activity recorded in direct solar data and proxies. Solar Physics 211, 371-394.

Pesaran, H., Y. Shin, and R. Smith (2000). Structural analysis of vector error correction models with exogenous I(1) variables. Journal of Econometrics 97, 293-343.

Phillips, P.C.B. and B.E. Hansen (1990). Statistical Inference in Instrumental Variables Regression with I(1) Processes. Review of Economics Studies 57, 99-125.

Phillips, P.C.B and P. Perron (1988). Testing for a Unit Root in Time Series Regression. Biometrika 75, 335-346.

Prather, M. (1994). Lifetimes and eigenstates in atmospheric chemistry. Geoplyysical Research Letters 21, 801-804.

Prather, M., D. Ehhalt, F. Dentener, R. Derwent, E.J. Dlugokencky, E. Holland, I. Isaksen, J. Katima, V. Kirchhoff, P. Matson, P. Midgley and M. Wang (2001). Atmospheric chemistry and greenhouse gases. in Climate Change 2001: The Scientific Basis, edited by J. T. Houghton et al., pp. 239-287, Cambridge Univ. Press, New York.

Qu, Z.N. and J.L. Xie (2013). Long-term periodicity variations of the solar radius. The Astrophysical Journal 762, 1-6.

Rahbek, A. and R. Mosconi (1999). Cointegration rank inference with stationary regressors in VAR models. Econometrics Journal 2, 76-91.

Robertson, A., J. Overpeck, D. Rind, E. Mosley-Thompson, G. Zielinski, J. Lean, D. Koch, J. Penner, I. Tegen and R. Healy, (2001). Hypothesized Climate Forcing Time Series for the Last 500 Years. Journal of Geophysical Research 106, 14783-14803.

Robinson, P.M. (1994). Efficient tests of nonstationarity hypotheses. Journal of the American Statistical Association 89, 1420-1437.

Ruddiman, W.F. (2003). The anthropogenic greenhouse era begun thousands of years ago. Climatic Change 61, 261-293.

Schwert, G.W. (1989). Tests for Unit-Roots: A Monte Carlo investigation. Journal of Business and Economic Statistics 7, 147-159. 
Singarayer, J.S., P.J. Valdes, P. Friedlingstein, S. Nelson and D.J. Beerling (2011). Late Holocene methane rise caused by orbitally controlled increase in tropical sources. Nature 470, 82-85.

Stern, D.I. and R.K. Kaufmann (1999). Econometric analysis of global climate change. Environmental Modelling and Software 46, 597-605.

Stern, D.I. and R.K. Kaufmann (2000). Detecting a Global Warming Signal in Hemispheric Temperature Series: A Structural Time Series Analysis. Climatic Change 47, 411-438.

Stern, D.I. and R.K. Kaufmann (2014). Anthropogenic and natural causes of climate change. Climatic Change 122, 257-269.

Tett, S.F.B., R. Betts, T.J. Crowley, J. Gregory, TC. Johns, A. Jones, T.J. Osborn, E. Öström, D.L. Roberts and M.J. Woodage (2007). The impact of natural and anthropogenic forcings on climate and hydrology since 1550. Climate Dynamics 28, 3-34.

Waggoner, P.E. and J.H. Ausubel (2002). A framework for sustainability science: a renovated IPAT identity. Proceedings National Academy of Sciences 99, 7860-7865.

Wang, Y., and D.J. Jacob (1998). Anthropogenic forcing on tropospheric ozone and OH since preindustrial times. Journal of Geophysical Research 103, 123-135.

West, K.D. (1988). Asymptotic normality when regressors have a unit root. Econometrica $56,1397-1418$.

Woodward, W.A. and H.L. Gray (1995). Selecting a Model for Detecting the Presence of a Trend. Journal of Climate 8, 1929-1937.

Woodward, W.A. and H.L. Gray (1993). Global Warming and the Problem of Testing for Trend in Time Series Data. Journal of Climate 6, 953-962. 